\title{
Increased susceptibility of estrogen-induced bladder outlet obstruction in a novel mouse model
}

\author{
Neville Ngai-Chung Tam ${ }^{1,2,3,5}$, Xiang Zhang ${ }^{1,2,3,5}$, Hong Xiao ${ }^{1,6}$, Dan Song ${ }^{1}$, Linda Levin ${ }^{1}$, Jarek Meller ${ }^{1,2,3}$ and \\ Shuk-Mei Ho $1,2,3,4$
}

Disorders of the prostate and lower urinary tract are common in elderly men. We investigated the role of metallothionein-1 (MT1) in prostate carcinogenesis by generating a prostate-specific, MT1-expressing mouse. Unexpectedly, genomic analyses revealed that a $12.1-\mathrm{kb}$ genomic region harboring several conserved noncoding elements was unintentionally deleted, upstream of the transgene integration site in the mouse, which we named it 12.1 $\Delta \mathrm{MT} 1$. Male 12.1 $\Delta \mathrm{MT} 1$ mice chronically treated with testosterone (T) plus $17 \beta$-estradiol (E2) to induce prostate cancer exhibited no evidence of precancerous or cancerous lesions. Instead, most of them exhibited a bladder outlet obstruction (BOO) phenotype not observed in treated wild-type (WT) mice. Thus, we hypothesized that $12.1 \Delta \mathrm{MT} 1$ is a novel model for studying the hormonal requirement for BOO induction. Adult male 12.1 $\triangle \mathrm{MT} 1$ and WT mice were treated with T, E2, bisphenol A (BPA), $\mathrm{T}+\mathrm{E} 2$, or T + BPA for up to 6 months. Histologic and immunohistochemical analysis of the prostate, bladder, and urethra were performed. No significant prostate pathologies were observed in WT or $12.1 \Delta \mathrm{MT} 1$ mice treated with any of the hormone regimens. As expected, prostatic regression occurred in all E2-treated animals (WT and 12.1 $\Delta \mathrm{MT1}$ ). Of great interest, despite a small prostate, $100 \%$ of E2-treated $12.1 \Delta \mathrm{MT} 1$ mice, but only $40 \%$ of E2-treated WT mice, developed severe $\mathrm{BOO}(P<0.01)$. In contrast, $\mathrm{T}+\mathrm{E} 2$ treatment was less effective than $\mathrm{E} 2$ treatment in inducing severe $\mathrm{BOO}$ in $12.1 \Delta \mathrm{MT} 1$ mice $(68 \%, P<0.05)$ and was completely ineffective in WT animals. Similarly, T, BPA, and T + BPA treatments did not induce $\mathrm{BOO}$ in either WT or $12.1 \triangle \mathrm{MT1}$ mice. The BOO pathology includes a thinner detrusor wall, narrowing of bladder neck and urethral lumen, and basal cell hyperplasia in the bladder body and urethra. These findings indicate that 12.1 $\triangle \mathrm{MT1}$ mice exhibit enhanced susceptibility to E2-induced BOO that is independent of prostate enlargement but that is attenuated by the conjoint treatment with $\mathrm{T}$.

Laboratory Investigation (2015) 95, 546-560; doi:10.1038/labinvest.2015.30; published online 23 February 2015

Bladder outlet obstruction (BOO) is regarded as a major cause of bothersome lower urinary tract symptoms (LUTS) in men. LUTS encompass a range of urinary morbidities, including those of storage, voiding, and postmicturition. ${ }^{1}$ The incidence and prevalence of LUTS increase with age. ${ }^{2}$ The etiologies of LUTS are multifactorial, and the pathophysiology is not well understood. ${ }^{1,3}$ LUTS has often been attributed to benign prostatic hyperplasia $(\mathrm{BPH})$, which narrows the urethral lumen and ultimately leads to BOO. However, a number of studies have suggested that $\mathrm{BOO}$ is not always caused by BPH. ${ }^{4-6}$ Factors or organs other than the prostate have been proposed as contributors to $\mathrm{BOO}$ or modifiers of the severity of its symptoms. ${ }^{3,7}$

An imbalance between androgens and estrogens has been implicated in the development of LUTS in men, including BOO. Higher levels of circulating $17 \beta$-estradiol (E2) were associated with an increased risk of LUTS in older men, ${ }^{8}$ and lower levels of circulating testosterone $(\mathrm{T})$ in men were correlated with increased severity of LUTS $^{9,10}$ and BOO. ${ }^{11}$ Male mice overexpressing aromatase developed BOO accompanied by morphologic changes and hyperproliferative responses in the urothelium and detrusor of bladder

\footnotetext{
${ }^{1}$ Department of Environmental Health, University of Cincinnati College of Medicine, Cincinnati, OH, USA; ${ }^{2}$ Center for Environmental Genetics, University of Cincinnati College of Medicine, Cincinnati, OH, USA; ${ }^{3} \mathrm{Cincinnati}$ Cancer Center, University of Cincinnati College of Medicine, Cincinnati, OH, USA and ${ }^{4}$ Cincinnati Veteran Affairs Hospital Medical Center, Cincinnati, OH, USA

Correspondence: Professor S-M Ho, PhD, Department of Environmental Health, University of Cincinnati College of Medicine, Room 130, Kettering Laboratory Complex,
} 3223 Eden Avenue, Cincinnati, OH 45267, USA.

E-mail: shuk-mei.ho@uc.edu

${ }^{5}$ These authors contributed equally to this work.

${ }^{6}$ Current address: Medpace, Cincinnati, OH, USA. 
body. $^{6} \mathrm{~T}$ plus $\mathrm{E} 2(\mathrm{~T}+\mathrm{E} 2)$ treatment was recently found to induce $\mathrm{BPH}$-related $\mathrm{BOO}$ symptoms in male mice. ${ }^{12}$ The $\mathrm{T}+\mathrm{E} 2$ regimen used to treat the mice in the present study has been reported to elevate the serum ratio of E2 to T, mimicking the hormonal milieu in aging men. ${ }^{13,14}$ In summary, excess E2 with a decline in T may promote the development of LUTS and/or its severity in elderly men. ${ }^{8-10}$ However, the effects and importance of E2 action on extraprostatic tissues/organs, including the lower urinary tract (LUT), are not well understood. Furthermore, a model in which LUTS can be studied in the absence of prostate enlargement has not been available until now. Finally, the role of bisphenol A (BPA), a ubiquitous environmental estrogen that has been shown to increase the risk of prostate cancer risk, ${ }^{15}$ in the etiology of LUTS has not yet been determined.

The genetic basis of LUTS, including BOO, is not well established. Genetic factors in LUTS have been suggested in twin studies. ${ }^{16} \mathrm{~A}$ recent genome-wide association study identified an association of a number of single-nucleotide polymorphisms with the severity of LUTS related to BPH. ${ }^{17}$ Data from the Encyclopedia of DNA Elements (ENCODE) projects suggest that regulatory DNA in 'non-gene' regions can regulate disease-associated gene networks and thereby influence the traits of complex diseases. ${ }^{18}$ It remains to be determined if specific regulatory DNA elements can determine the risk, susceptibility, and severity of LUTS and/BOO. To our knowledge, there are no animal models for the study of the function of regulatory DNA elements in LUTS/BOO.

Metallothioneins (MTs), a family of cysteine-rich proteins with a strong affinity for metals, are involved in cell proliferation, apoptosis, and neoplastic transformation in the prostate gland. ${ }^{19}$ In the present study, our initial goal was to explore the role of MT1 in hormone-induced prostate carcinogenesis in vivo. To this end, using the androgencontrolled prostate-specific probasin promoter, we successfully generated a prostate-specific MT1 expressor. However, neither prostate cancer nor prostate intraepithelial neoplasia (a precancerous lesion) developed spontaneously in this transgenic mouse or in those treated with $\mathrm{T}$ and/or E2. To our surprise, we observed bladder enlargement with urinary retention, symptoms consistent with human BOO/LUTS, in all E2-treated mice and in $68 \%$ of the $\mathrm{T}+\mathrm{E} 2$-treated mice, without or with prostate enlargement, respectively. The prevalence of these urologic symptoms was either much lower in the E2-treated (40\%) mice or absent in the T + E2treated wild-type (WT) mice. As E2 treatment reduced prostate size and did not induce MT1 overexpression in the prostate, we concluded that the induction of these urologic symptoms was not related to MT overexpression or prostate enlargement even in the $\mathrm{T}+\mathrm{E} 2$-treated mice. Thus, we believe that we have generated a transgenic animal with heightened susceptibility to E2-induced BOO/LUTS, independent of prostate enlargement.

We characterized the transgenic mouse further by genetic mapping and identified a single transgene integration site on chromosome (chr) 16. However, we found that a $12.1-\mathrm{kb}$ genomic region upstream of this site was deleted. Hence, we named this mouse 12.1 $\Delta \mathrm{MT} 1$. Bioinformatic analysis identified several highly conserved noncoding elements within the deleted genomic region, raising the question of whether potential regulatory DNA elements residing in the deleted region contribute to the etiology. The analysis also identified Grin2a, which encodes NMDAR2A, a subunit of the Nmda receptor, as the nearest coding gene upstream of the genomic disrupted region. As the Nmda receptor controls the neural circuitry of the micturition reflex pathway, ${ }^{20}$ we also examined the expression of Grin2a immunocytochemically in our mouse model.

In summary, we posit that $12.1 \Delta \mathrm{MT} 1$ is an excellent model for studying the hormonal and genetic determinants involved in the natural history of $\mathrm{BOO}$ in a manner independent of the prostate pathology.

\section{MATERIALS AND METHODS \\ Animals}

To generate transgenic mice expressing MT1 and luciferase (as a surrogate marker of transgene expression) specifically in the prostate, we prepared a transgene construct consisting of modified rat probasin promoter ARR2 $\mathrm{PB}^{21}$ that linked to the downstream myc epitope-tagged mouse MT1 coding sequence, followed by an internal ribosome entry site (IRES) and luciferase gene (Figure 1a and Supplementary Table S1). We validated that the transgene expression of both MT1 and luciferase was induced by the androgen analog R1881 in human LNCaP prostate cancer cells (Figures $1 \mathrm{~b}$ and c). Transgenic mice were produced by standard pronuclear injection techniques and confirmed by PCR genotyping of tail snips (Figure 1d and Supplementary Table S2 for primer information). To confirm the tissue specificity of transgene expression in mice, we measured luciferase activity in prostate and other tissues/organs, including the bladder body and neck. To determine the expression levels of transgene and endogenous MT1, total RNA was extracted from prostate samples, and we performed reverse transcription and realtime quantitative PCR. The production and characterization of transgenic mice are described in Supplementary Materials and Methods. The protocols for animal use were approved by the Institutional Animal Care Committee at the University of Cincinnati and the University of Massachusetts Medical School.

\section{Identification and Validation of Integration Site}

The MT1 transgene integration site(s) was identified by MCLAB (South San Francisco, CA, USA). The integration site was validated by performing a series of PCR targeting MT1 constructs and flanking expected integration site determinations (Supplementary Table S2 for primer information). The PCR products were then gel purified and sequenced (Macorgen USA, Rockville, MD, USA). A BLAST 
a

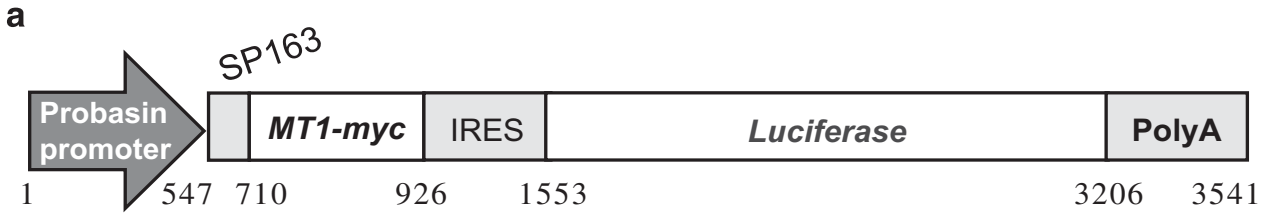

b
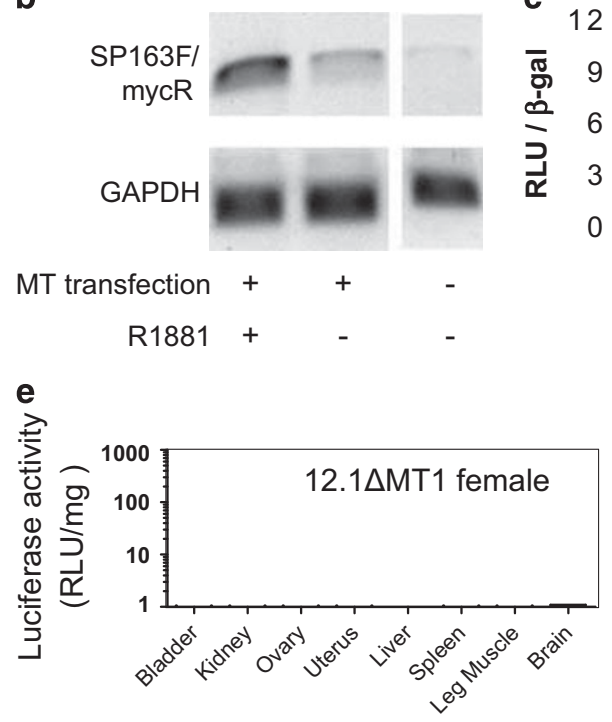

d

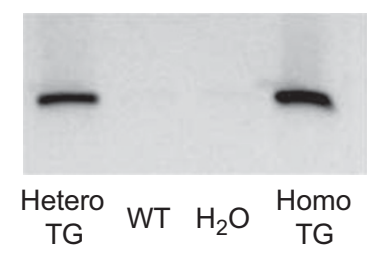

\section{f}

\section{Chromosome 16}

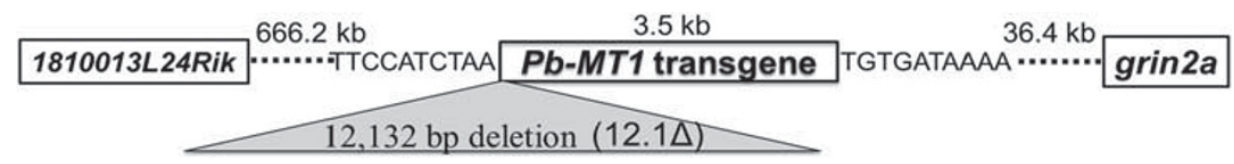

Figure 1 Characterization of metallothionein-1 (MT1) construct and 12.1 $\Delta$ MT1 transgenic mouse. (a) Organization of a 3541-bp MT1 transgene construct expressing mouse MT1 and luciferase (luc). Androgen-responsive prostate-specific probasin-promoter ARR2PB is linked to SP163 translational enhancer for increased myc-tagged MT1 expression. The downstream IRES allows independent translation initiation of the Luc gene, which is an appended polyA signal to stabilize the transcript. (b) Androgen upregulates MT1 transgene expression in LNCaP prostate cancer cells. Semiquantitative reverse transcription-PCR (RT-PCR) showed that the androgen analog R1881 stimulated the transcription of foreign MT1. GAPDH was used as a housekeeping gene control. (c) Co-transfection of MT1 construct with $\beta$-gal expression plasmid (pCMV-LacZ) in LNCaP cells exhibited elevated luciferase activity (RLU) in response to R1881 treatment. RLU is normalized to $\beta$-gal activity. (d) Genotyping with the construct-specific primers showed specific amplification in the transgenic (hetero- and homo-) mice but not wild-type (WT) mice. (e) Major luciferase signals were derived from adult prostate dorsolateral (DLP) and ventral lobes (VP). Minor reporter signals were detected in bladder neck, urethra, seminal vesicle (SV), and testes. Residual prostate tissues probably contribute to the low levels of luciferase reporter activity in bladder neck and urethra. Luminescence was almost undetectable in all female tissues. Wild-type (WT) brain was a negative control for luciferase assays. (f) Identification of the MT1 insertion site. A single insertion site was identified in one line of the transgenic mice at chromosome 16. A 12.1-kb deleted region was identified immediately upstream of the insertion site. The insertion site is $36.4 \mathrm{~kb}$ upstream of Grin2a and $666.2 \mathrm{~kb}$ downstream of 1810013L24Rik gene.

search was used to validate the integration site and its flanking regions.

\section{Detection of Genomic DNA Deletion Upstream of the Integration Site}

Because the expected mouse genomic DNA sequence immediately upstream of the insertion site was not detected by PCR, we used a series of forward primers further upstream of the integration site, together with the probasin promoterspecific reverse primer, to probe the deletion region (Supplementary Table S2).

\section{Hormone Treatment and Histologic Analysis}

WT and homozygous $12.1 \Delta \mathrm{MT} 1$ transgenic male mice were randomized into six treatment groups: control, E2, BPA, T, $\mathrm{T}+\mathrm{E} 2$, and $\mathrm{T}+\mathrm{BPA}$. Control mice were surgically implanted with empty capsules. Treated mice were surgically implanted with silastic capsules containing hormones for 4 to 6 months, as described previously. ${ }^{13,22}$ The combined treatment with $\mathrm{T}$ and E2, used in the current study, has been well established as recapitulating the hormonal milieu in aging men. ${ }^{13,14}$ The T-, E2-, and BPA-filled capsules contained $25 \mathrm{mg}$ T, $2.5 \mathrm{mg}$ $\mathrm{E} 2$, and $10 \mathrm{mg} \mathrm{BPA}$, respectively. The hormone dosage of the 
respective groups is shown in Supplementary Table S3. Animals were kept under standard conditions and fed a soy-free AIN76A diet (Test Diet, Richmond, IN, USA) and drinking water ad libitum. Mice were killed with an overdose of isoflurane. Urine was collected from bladders for volume measurement. The genitourinary complex containing bladder body, bladder neck, seminal vesicle, prostate, and proximal urethra was excised and processed for histologic analysis. Tissue sections were stained with Masson's Trichrome stain to identify extracellular collagen.

\section{Immunohistochemistry}

Serial sections $(7 \mu \mathrm{m}$ thick) were cut along the LUT containing bladder body, bladder neck, and proximal urethra with surrounding prostate glands and seminal vesicles. Primary antibodies to uroplakin III (1:300 dilution, sc-15186; Santa Cruz Biotechnology, Santa Cruz, CA, USA), Ki67 (1:150 dilution, SP6; Abcam, Cambridge, MA, USA) and NMDAR2A (an NMDA receptor subunit encoded by Grin2a; 1:300 dilution, PA5-27921; Thermo Scientific, Rockford, IL, USA) were incubated with sections overnight at $4{ }^{\circ} \mathrm{C}$. Antigen retrieval by microwave heating with $0.01 \mathrm{M}$ citrate buffer, $\mathrm{pH}$ 6.0, was performed before incubation with primary antibodies to uroplakin III and Ki67. Sections were then incubated with biotinylated anti-rabbit or anti-goat antibodies (Vector Laboratories, Burlingame, CA, USA), followed by incubation with avidin-biotin-peroxidase complex (Vector Laboratories). Immunoreactivity was visualized by incubation with DAB chromagen (Sigma, St Louis, MO, USA).

\section{Statistical Analysis}

The statistical analyses of the retention of urine and the thickness of detrusor evaluated mean differences between WT and 12.1 $\Delta \mathrm{MT} 1$ transgenic mice for each of the six groups of mice, including five treatments and one control group, using an analysis of variance (ANOVA) model. Paired comparisons of group differences within each mouse type were evaluated by $T$-tests within the ANOVA. Differences in incidences of severe urinary retention across treatment groups or mouse types were also evaluated. Statistical methodologies included non-zero negative binomial regression, linear regression using GEE (generalized estimating equations), Fisher's exact test, and Firth logistic regression. $P$-values were adjusted for multiple comparisons by the Bonferroni method. A significance level of 0.05 was assumed to indicate statistical significance, unless stated otherwise. Analyses were performed using SAS for Windows, version 9.3.

\section{RESULTS}

\section{Generation of Prostate-Specific MT1 Transgenic Mice}

To achieve our initial goal of determining the role of MT1 in prostate carcinogenesis, we generated transgenic mice expressing MT1 and luciferase specifically in the prostate gland. We studied two independent lines of transgenic founders, one of which had an unsatisfactory reproductive phenotype, as evidenced by small litter size, frequent cannibalism, and poor health of the offspring in the establishment of a homozygous colony. The transgenic line MT1 with fertile homozygous breeders generating healthy offspring was further established for subsequent characterization and experiments. A luciferase assay confirmed the prostate-specific transgene expression in male mice, with no or negligible activity detected in other tissues/organs, including the bladder body and neck (Figure 1e). Real-time qRT-PCR analysis confirmed the expression of transgene MT1 in ventral prostates (VPs) of $12.1 \Delta \mathrm{MT} 1 \mathrm{mice}$, but the expression was undetectable in WT VPs. Treatment with E2 reduced the levels of both transgene and endogenous MT1 in VPs of 12.1 $\triangle \mathrm{MT} 1$ mice. The cycle threshold (CT) values of PCRs of transgene MT1 was greater than those of endogenous MT1 by a difference of 10 to 12 cycles. This observation suggests that the abundance of transgene MT1 transcripts was relatively low compared with the endogenous MT1 pool in the VP of $12.1 \Delta \mathrm{MT} 1$ mice (Supplementary Table S4).

\section{Identification of Transgene Integration Loci and Genomic Deletion in Homozygous Transgenic Mice}

We identified only one integration site, which is at chr 16 (Figure 1f). Multiple PCRs with different primers (Supplementary Table S2) showed the intact sequence of the inserted 3.5-kb transgene construct and its downstream genomic DNA sequence. However, genetic mapping by PCRs interrogating the upstream region of the integration site indicated a deletion of mouse genome. Genomic sequencing analysis confirmed a deletion of $12132 \mathrm{bp}$ upstream of the insertion site (Figure 1f and Supplementary Table S5).

\section{Bioinformatic Analysis of the Insertion Site and the Deleted region}

Bioinformatic analysis with Ensembl (http://www.ensembl. org), UCSC Genome Browser (http://genome.ucsc.edu/), GenBank (http://www.ncbi.nlm.nih.gov), and by BLAST and related sequence alignment methods showed that the concurrent site of MT1 transgene insertion and 12.1-kb genomic deletion (mouse chr 16: $9525278-9537409$ ) was located in an intergene region $\sim 666 \mathrm{~kb}$ downstream of the gene 1810013 L24Rik and $\sim 36 \mathrm{~kb}$ upstream of the downstream gene, Glutamate Receptor, Ionotropic, NMDA2A (epsilon 1) and (Grin2a) (Figures $2 \mathrm{a}$ and b). Further analysis with the Genomatix software suite (http://www.genomatix.de) revealed no putative transcripts, microRNA, promoter, or transcription start sites in the deleted region. However, this region contains several regions that are well conserved among eutherian mammals, including two highly conserved elements corresponding to positions chr 16: 9533119 9533235 and $9533422-9533461$ in the mouse genome, as mapped by Ensembl (Figure 2c) and confirmed by sequence alignment methods (data not shown). We also mapped 


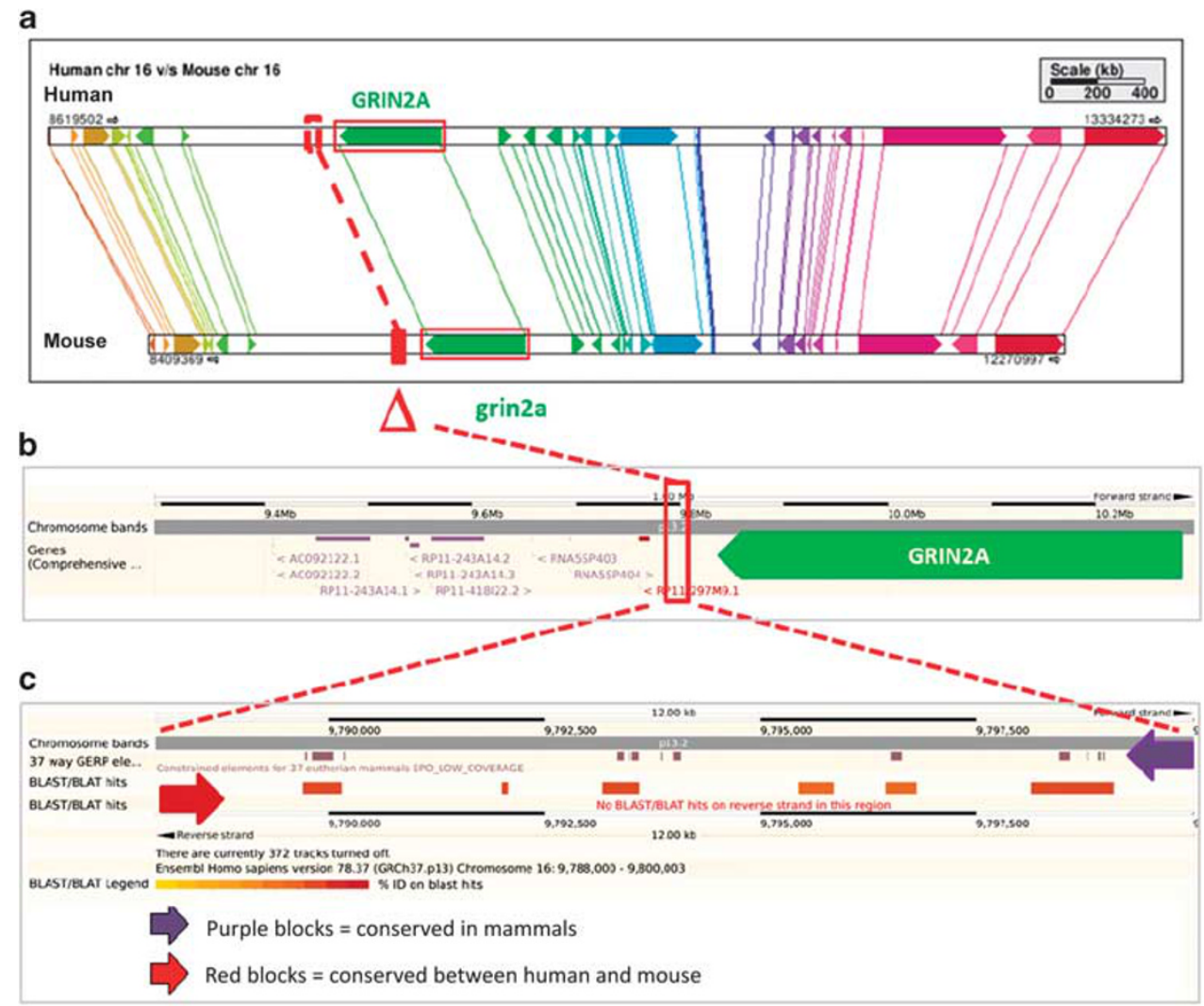

Figure 2 Mapping conserved noncoding elements within the deleted fragment in the vicinity of Grin2a gene. (a) Extensive synteny around the Grin2a and its human GRIN2A counterpart is illustrated with the Cinteny server (http://cintemy.cchmc.org); the syntenic block around GRIN2A is flanked by ABAT and SHISA9 genes; the location of the deleted fragment (in red) is indicated by $\triangle$. (b) Mapping the deleted fragment into the human genome; the location of the human counterpart of the deleted region $(\Delta)$ is indicated with red frame upstream of GRIN2A gene using Ensembl (http://www.ensembl.org). (c) Enlarged view of the human counterpart of the deleted fragment, with best aligning fragments with mouse genome (BLASTn alignments with significant $E$-values) indicated by red rectangles; note the location of several mammalian conservation regions (purple rectangular blocks) within two of the aligned fragments.

ENCODE elements into the human counterpart of the deleted region that contain two DNase I hypersensitivity clusters, suggesting potential cis-regulatory DNA elements (data not shown). To identify putative regulatory sites within the deleted region, we used ECR browser (http://ecrbrowser. dcode.org/) to further map and analyze evolutionary conserved (between human and mouse) regions within the deleted fragment in the vicinity of Grin $2 a$ gene. Subsequently, rVista (http://rvista.dcode.org/cgi-bin/rFromXB.cgi) was used to identify conserved TF binding sites in these regions (Supplementary Figure S1).

\section{No Prostate Pathology Observed in Untreated or Hormone-Treated WT and 12.1 $\triangle \mathrm{MT} 1$ Mice}

No premalignant or cancerous lesions were detected in the prostate glands of WT and 12.1 $\mathrm{MT} 1$ mice with or without hormone treatment (E2, $\mathrm{T}+\mathrm{E} 2, \mathrm{~T}, \mathrm{BPA}$, or $\mathrm{T}+\mathrm{BPA})$. The $\mathrm{T}+\mathrm{E} 2-$, $\mathrm{T}-$, and $\mathrm{T}+\mathrm{BPA}$-treated prostates and seminal vesicles were larger than those of untreated control mice. E2 treatment caused a remarkable regression of prostate glands and seminal vesicles.

\section{1 $\triangle$ MT1 Mice are More Susceptible than WT Mice to Estrogen Induction of BOO}

After mice were treated for 4-6 months with E2 (inducing prostatic involution) or $\mathrm{T}+\mathrm{E} 2$ (causing prostatic enlargement), we consistently observed dilated bladder with urine retention in 12.1 $\Delta \mathrm{MT} 1$ mice and an enlarged bladder in some WT mice (Figures $3 \mathrm{a}$ and $\mathrm{b}$ ). Untreated WT or 12.1 $\Delta \mathrm{MT} 1$ mice and $\mathrm{T}+\mathrm{E} 2$-treated $\mathrm{WT}$ mice showed no signs of the BOO phenotype. The urine volume was significantly greater in E2-treated 12.1 $\Delta \mathrm{MT} 1$ mice (mean: $3.5 \mathrm{ml}$; 95\% confidence interval $(\mathrm{CI}): 2.0-6.1 \mathrm{ml}$ ) than E2-treated WT (mean: $1.0 \mathrm{ml} ; 95 \% \mathrm{CI}: 0-2.3 \mathrm{ml} ; P<0.05$ ) or untreated control 12.1 $\Delta \mathrm{MT} 1$ mice (mean: $0.1 \mathrm{ml}$; $95 \%$ CI: $0.0-0.2 \mathrm{ml}$; $P<0.01)$. The volume of urine retained was also significantly increased in T+E2-treated 12.1 $\mathrm{MT} 1$ mice (mean: $1.6 \mathrm{ml}$; 95\% CI: $1.1-2.4 \mathrm{ml}$ ) as compared with that of T + E2-treated WT (mean: $0.06 \mathrm{ml}$; $95 \%$ CI: $0.02-0.2 \mathrm{ml}, P<0.01$ ) or untreated $12.1 \Delta \mathrm{MT} 1$ mice (mean: $0.1 \mathrm{ml}$; $95 \%$ CI: $0.08-0.2 \mathrm{ml}$; $P<0.01)$. The incidence of mice exhibiting severe $\mathrm{BOO}$ symptoms that retained $>1 \mathrm{ml}$ of urine is shown in Table 1 . Among $12.1 \Delta \mathrm{MT} 1$ mice treated with $\mathrm{E} 2$ or $\mathrm{T}+\mathrm{E} 2$, the 
a

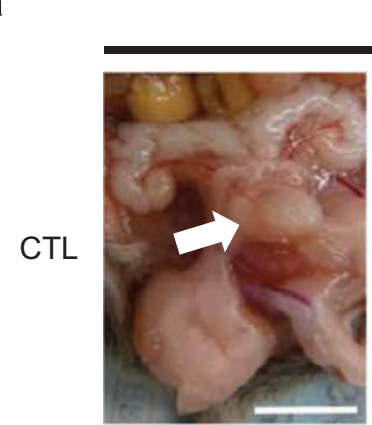

WT

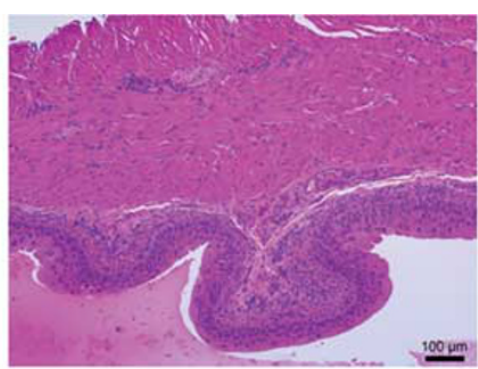

$1004 \mathrm{~m}$
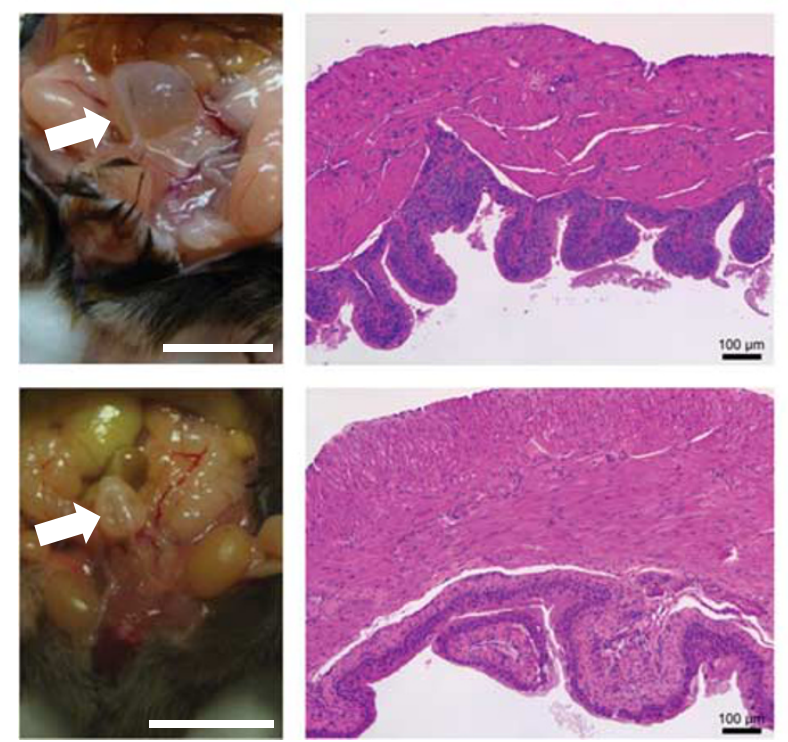

12.1 $\triangle \mathrm{MT} 1$
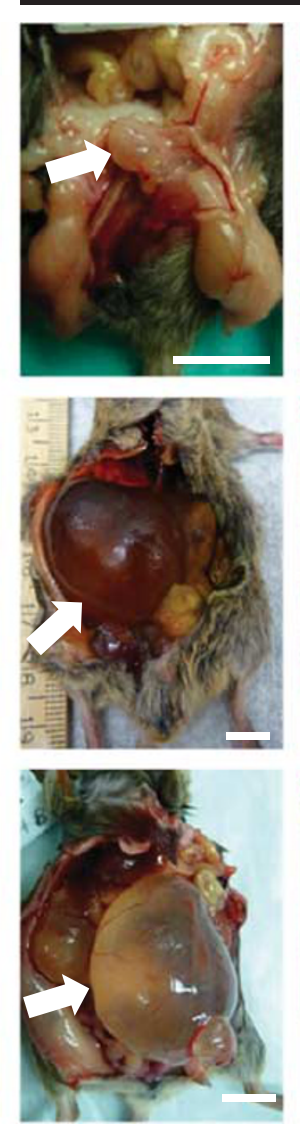
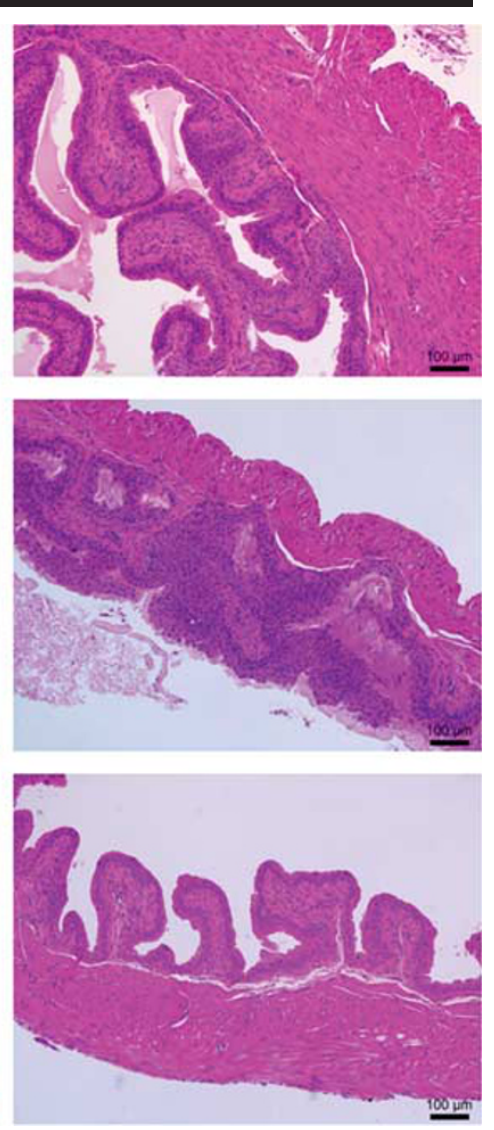

b

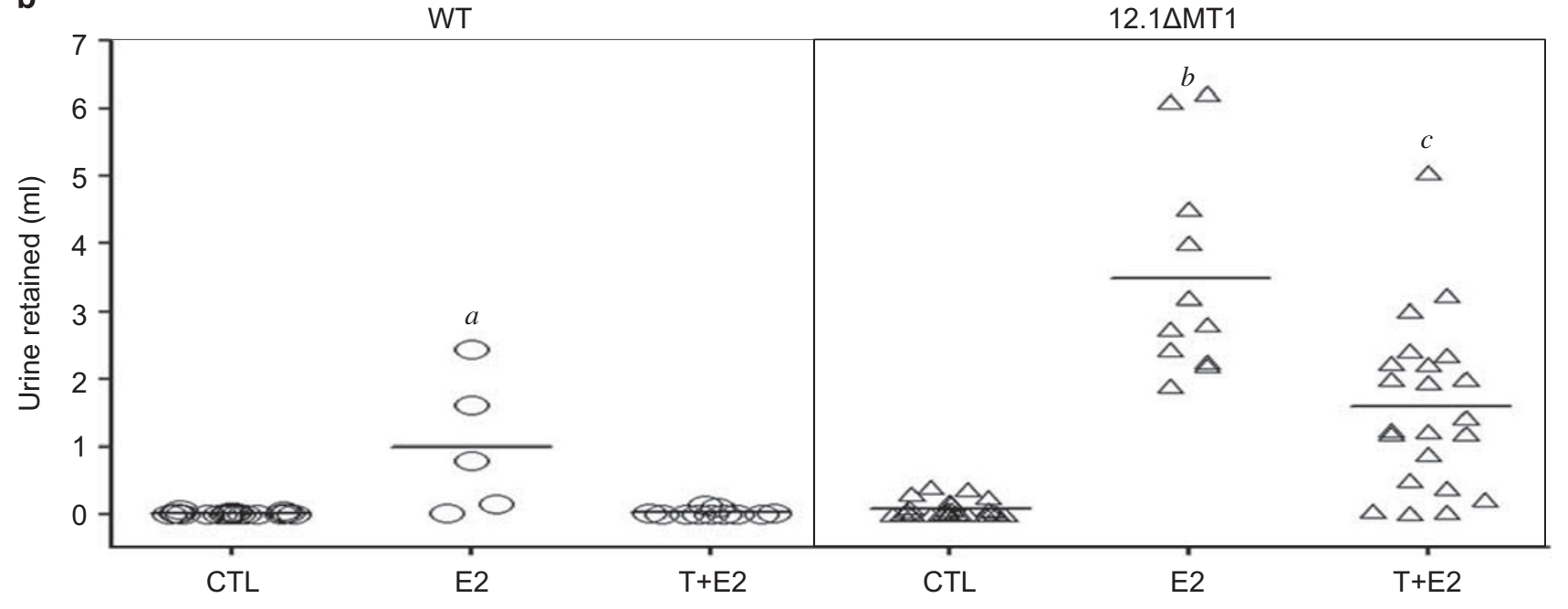

Figure 3 Effects of sex hormone treatments on urinary retention and detrusor thickness in the bladders of wild-type (WT) and 12.1 $\Delta$ MT1 mice. (a) Gross images and hematoxylin and eosin (H\&E)-stained sections of bladders. The bladders of untreated WT and 12.1 $\Delta$ MT1 control mice are small and deflated with little or no urine retained and a typically thick detrusor. After treatment with 17 $\beta$-estradiol (E2) or testosterone (T) +E2, 12.1 $\Delta$ MT1 mice exhibited severe bladder outlet obstruction (BOO), as marked by a massively enlarged bladder with urine retention and a thin detrusor as compared with WT mice. Some E2-treated WT mice showed only a mild degree of urinary retention and reduction in detrusor thickness. T+E2-treated WT mice showed no signs of severe BOO. White arrows: urinary bladder. White scale bar: $1 \mathrm{~cm}$; black scale bar: $100 \mu \mathrm{m}$. (b) The graph depicts the volume of urine retained in bladders of individual mice across treatment groups. The average volume of urine retained was significantly increased in the bladders of E2-treated WT mice as compared with untreated or T + E2-treated WT mice. The average volume of urine retained in 12.1 $\Delta \mathrm{MT1}$ mice with E2 or T+E2 treatment was significantly greater than that of WT mice with respective treatment. a, vs WT: CTL, or WT: T+E2, $P<0.01$. b, vs $12.1 \Delta \mathrm{MT1}: \mathrm{CTL}, P<0.01$, and vs WT: E2, $P<0.05$. C, vs 12.1 $\triangle \mathrm{MT1}$ : CTL, $P<0.01$, and vs WT: $T+E 2, P<0.01$. Horizontal bars: average volume of urine retained. MT1, metallothionein-1. 
Table 1 Incidence of urine retention in bladders with volume $>1 \mathrm{ml}^{\text {b }}$

\begin{tabular}{|c|c|c|c|c|c|c|}
\hline \multirow[t]{2}{*}{ Treatment } & \multicolumn{3}{|c|}{ WT } & \multicolumn{3}{|c|}{$12.1 \Delta \mathrm{MT} 1$} \\
\hline & $\begin{array}{l}\text { Total no. } \\
\text { of mice }\end{array}$ & $\begin{array}{l}\text { No. of mice with } \\
\text { urine retention }>1 \mathrm{ml}\end{array}$ & $\begin{array}{l}\text { Incidence } \\
(\%)\end{array}$ & $\begin{array}{l}\text { Total no. } \\
\text { of mice }\end{array}$ & $\begin{array}{l}\text { No. of mice with } \\
\text { urine retention }>1 \mathrm{ml}\end{array}$ & $\begin{array}{c}\text { Incidence } \\
(\%)\end{array}$ \\
\hline CTL & 21 & 0 & 0 & 25 & 0 & 0 \\
\hline E2 & 5 & 2 & 40 & 11 & 11 & $100^{\mathrm{a}, \alpha}$ \\
\hline T & 5 & 0 & 0 & 13 & 0 & 0 \\
\hline BPA & 5 & 0 & 0 & 8 & 0 & 0 \\
\hline $\mathrm{T}+\mathrm{BPA}$ & 5 & 0 & 0 & 8 & 0 & 0 \\
\hline
\end{tabular}

${ }^{\mathrm{a}} P<0.05$ vs $12.1 \Delta \mathrm{MT} 1-\mathrm{T}+\mathrm{E} 2$.

${ }^{\alpha} P<0.01$ vs WT $-E 2$.

${ }^{\beta} P<0.01$ vs WT $-\mathrm{T}+\mathrm{E} 2$.

${ }^{\mathrm{b}}$ The volume of $1 \mathrm{ml}$ is an arbritury cutoff value for severe symptom of BOO.

Table 2 Hormonal effects on the bladder detrusor thickness of WT and 12.1 $\Delta \mathrm{MT} 1$ mice

\begin{tabular}{|c|c|c|c|c|c|c|}
\hline \multirow[t]{2}{*}{ Treatment } & \multicolumn{3}{|c|}{ WT } & \multicolumn{3}{|c|}{$12.1 \Delta \mathrm{MT} 1$} \\
\hline & $N$ & Mean thickness ${ }^{\mathrm{a}}(\mu \mathrm{m})$ & 95\% Confidence intervals & $N$ & Mean thickness ${ }^{a}(\mu \mathrm{m})$ & $95 \%$ Confidence intervals \\
\hline CTL & 6 & 454 & $383-538$ & 7 & 460 & $393-538$ \\
\hline E2 & 5 & 421 & $350-507$ & 6 & $230^{\mathrm{b}, \alpha}$ & $194-273$ \\
\hline$T+E 2$ & 5 & 498 & $414-600$ & 5 & $291^{c, \beta}$ & $241-350$ \\
\hline BPA & 5 & 363 & $301-437$ & 5 & $285^{c}$ & $236-343$ \\
\hline $\mathrm{T}+\mathrm{BPA}$ & 5 & 402 & $333-484$ & 6 & 344 & $290-408$ \\
\hline
\end{tabular}

${ }^{\mathrm{a}} \mathrm{Geometric} \mathrm{means} \mathrm{of} \mathrm{bladder} \mathrm{detrusor} \mathrm{thickness.}$

${ }^{\mathrm{b}} \mathrm{P}<0.01$ vs $12.1 \Delta \mathrm{MT} 1-\mathrm{CTL}, P<0.05$ vs $12.1 \Delta \mathrm{MT} 1-\mathrm{T}$.

${ }^{\mathrm{C}} P<0.05$ vs $12.1 \Delta \mathrm{MT} 1-\mathrm{CTL}$.

${ }^{\alpha} P<0.001$ vs WT $-E 2$.

${ }^{\beta} P<0.01$ vs WT $-\mathrm{T}+\mathrm{E} 2$.

incidence of severe $\mathrm{BOO}$ was significantly higher than among WT mice with the respective treatment (12.1 $\Delta$ MT1-E2: 100\% vs WT-E2: $40 \%, P<0.01 ; 12.1 \Delta \mathrm{MT} 1-\mathrm{T}+\mathrm{E} 2: 68.2 \%$ vs WT$\mathrm{T}+\mathrm{E} 2: 0 \%, P<0.01)$. However, $\mathrm{T}, \mathrm{BPA}$, or $\mathrm{T}+\mathrm{BPA}$ treatment did not cause urinary retention in bladders of either WT or 12.1 $\triangle \mathrm{MT} 1$ mice (Supplementary Table S6). E2, $\mathrm{T}+\mathrm{E} 2$, or BPA treatment caused a significant reduction in the thickness of detrusor in $12.1 \Delta \mathrm{MT} 1$ mice but not in WT mice (Figure 3a and Table 2).

\section{Estrogens Reduced the Luminal Sizes of Bladder Neck and Proximal Urethra}

To identify bladder neck in a LUT region, we used an immunohistochemical approach with an antibody to uroplakin III, which is a marker of urethelial differentiation (Figure 4a). The luminal size of the bladder neck of untreated WT mice was comparable to that of untreated $12.1 \Delta \mathrm{MT} 1$ mice. Following exposure to E2, the luminal size of the bladder neck was remarkably reduced in WT and $12.1 \Delta \mathrm{MT} 1$ mice. Treatment with $\mathrm{T}+\mathrm{E} 2$ also caused narrowing of the bladder neck in $12.1 \Delta \mathrm{MT} 1$ mice but not in WT mice.

Next, we examined the proximal urethra, which is defined as the portion of the urethra cranial to the verumontanum that contains the ejaculatory ducts and the main ducts of the seminal vesicles. ${ }^{12}$ There were no noticeable differences in the luminal size of the proximal urethra in untreated WT mice and untreated $12.1 \Delta \mathrm{MT} 1$ mice (Figure $4 \mathrm{~b}$ ). Treatment with E2 caused urethral narrowing in WT and 12.1 $\Delta \mathrm{MT} 1$ mice, whereas treatment with $\mathrm{T}+\mathrm{E} 2$ did not. Treatment with $\mathrm{T}$ alone, $\mathrm{BPA}$ alone, or $\mathrm{T}+\mathrm{PBA}$ did not change the luminal size of the bladder neck and proximal urethra in WT and 12.1 $\Delta \mathrm{MT} 1$ mice (data not shown). 


\section{Estrogens Promoted Fibrosis in the Bladder Body and Bladder Neck}

To demonstrate LUT fibrosis associated with the late stage of BOO, we performed Masson's Trichrome stain to identify the extracellular collagen in bladder body (Figure 5a), bladder neck (Figure 5b), and proximal urethra (Supplementary Figure S2). In both untreated WT and $12.1 \Delta \mathrm{MT} 1$ mice, collagen staining was primarily located in the lamina propria of bladder body and bladder neck. E2 alone markedly increased collagen infiltration into the detrusor smooth muscle layer of bladder body and bladder neck of WT and 12.1 $\mathrm{MT} 1$ mice. Conspicuous collagen staining was occasionally observed in the bladder-neck urothelium of WT and 12.1 $\Delta \mathrm{MT} 1$ mice treated with E2. T $+\mathrm{E} 2$ treatment caused a mild increase in collagen deposition in the detrusor of bladder body and bladder neck of $12.1 \Delta \mathrm{MT} 1$ mice but not in WT mice. In the proximal urethra, collagen staining was abundant in the connective tissue but not in the striated muscle layer of untreated, E2- or T+E2-treated WT and 12.1 $\Delta \mathrm{MT} 1$ mice, respectively. a

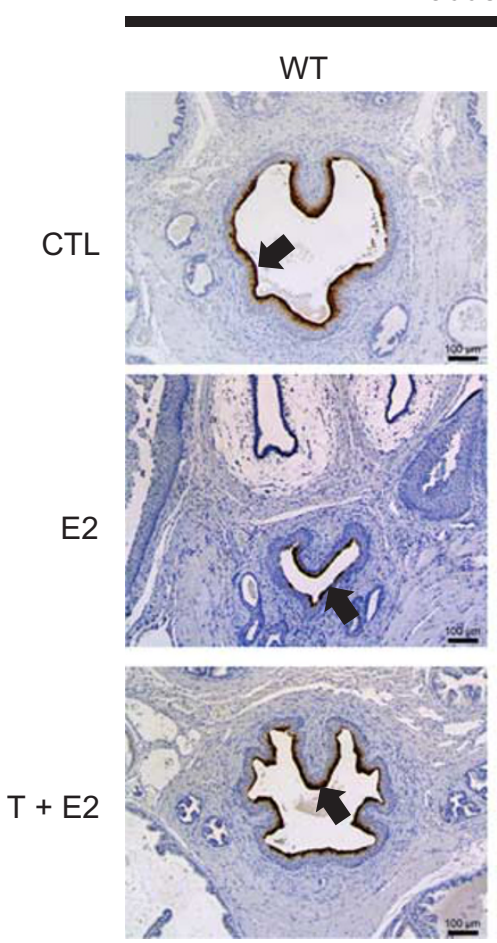

Bladder neck
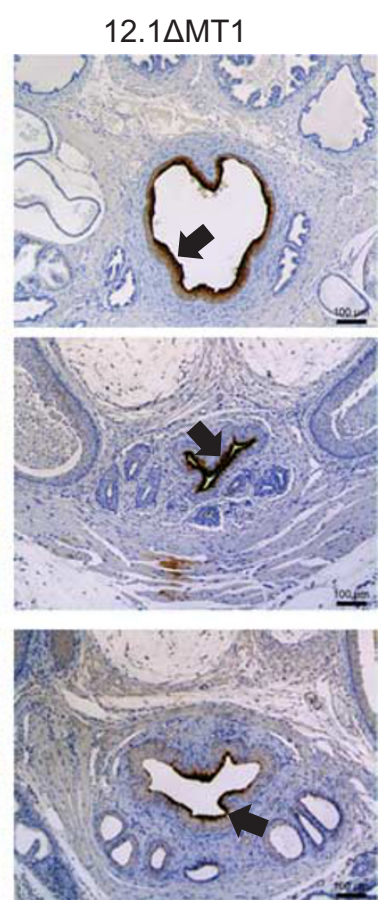

b

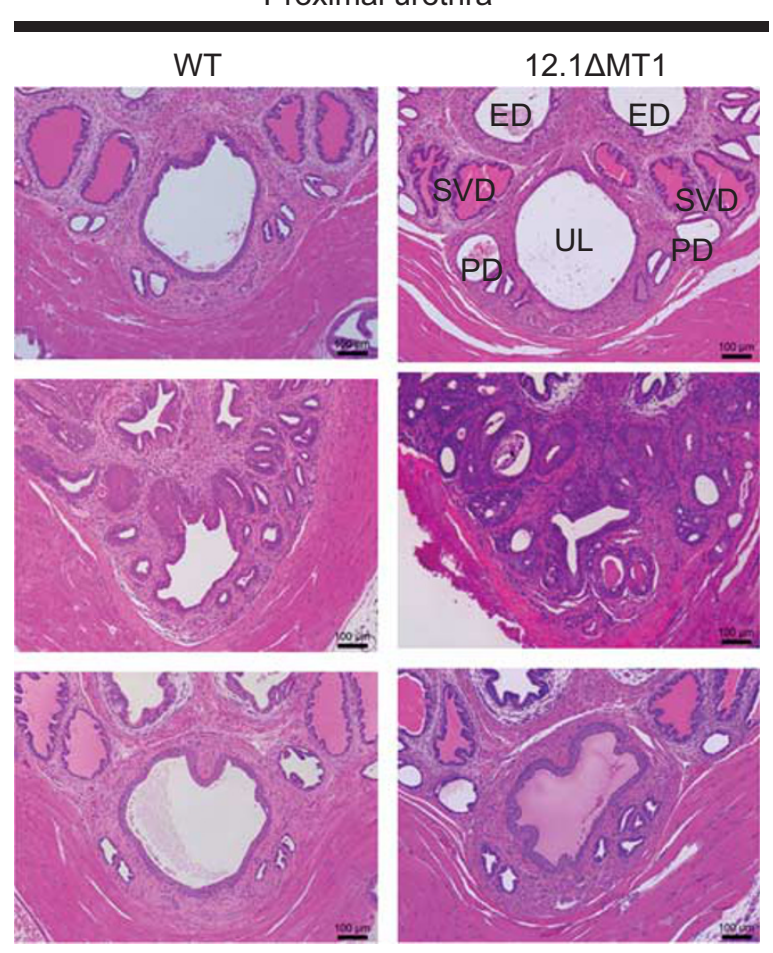

Figure 4 Effects of $17 \beta$-estradiol (E2) and testosterone (T) + E2 on the morphology of the (a) bladder neck and (b) proximal urethra of WT and 12.1 $\mathrm{MTT} 1$ mice. (a): The presence of uroplakin III immunostaining (arrows) marks the urothelium of the bladder neck in the representative sections. 12.1 $\Delta \mathrm{MT1}$ mice treated with E2 or T + E2 had a small bladder-neck lumen as compared with untreated 12.1 $\Delta \mathrm{MT1}$ control mice. E2 also caused a remarkable narrowing of the bladder-neck lumen in some WT mice. (b) E2 had markedly narrowed the urethral lumen in 12.1 $\Delta$ MT1 mice and some WT mice, whereas the narrowing effects of T+E2 were less pronounced than those of E2. The image of untreated control $12.1 \Delta M T 1$ mice is used as an example to illustrate the location of urethral lumen (UL), prostatic ducts (PD), seminal vesicle ducts (SVD), and ejaculatory ducts (ED). MT1, metallothionein-1.

Figure 5 Effects of $17 \beta$-estradiol (E2) and testosterone (T) +E2 treatment on fibrosis of the (a) bladder body, (b) bladder neck of WT and 12.1 $\Delta M T 1$ mice. Masson's Trichrome stain reveals collagen (blue) and cells (red). (a) In untreated WT or 12.1 $\Delta \mathrm{MT1}$ mouse bladders, collagen staining was located in the lamina propria, but was rather sparse in the detrusor smooth muscle layer. After E2 treatment, WT or 12.1 $\Delta$ MT1 mouse bladders showed a remarkable increase in collagen staining within the detrusor smooth muscle layer. After T+E2 treatment, noticeable collagen staining was focally detected in the detrusor of 12.1 $\mathrm{MTT} 1$ mouse bladders, whereas no or little collagen staining was observed in those of WT mouse bladders. (b) In untreated WT or 12.1 $\mathrm{M}$ MT1 mouse bladder necks, collagen staining was detected in the lamina propria, but was scant in the smooth muscle layer. E2 alone caused a marked increase in collagen staining within the smooth muscle layer and focal regions of the bladder-neck urothelium of WT or 12.1 $\Delta \mathrm{MT} 1$ mice. T+E2 treatment increased the amounts of collagen in the smooth muscle layer of $12.1 \Delta \mathrm{MT} 1$ mouse bladder necks, but not in WT mouse bladder necks. High power panel (right): high magnification of a region outlined by black lines in the respective images of the low power panel (left). Scale bar (high power panel): $200 \mu \mathrm{m}$. Scale bar (low power panel): $100 \mu \mathrm{m}$. Green border arrows: no or little collagen staining in the smooth muscle layer. Orange solid arrows: collagen staining in the lamina propria. Green solid arrows: a marked increase in collagen staining within the smooth muscle layer. White solid arrows: collagen staining within the bladder-neck urothelium. *Bladder lumen. MT1, metallothionein-1. 
WT

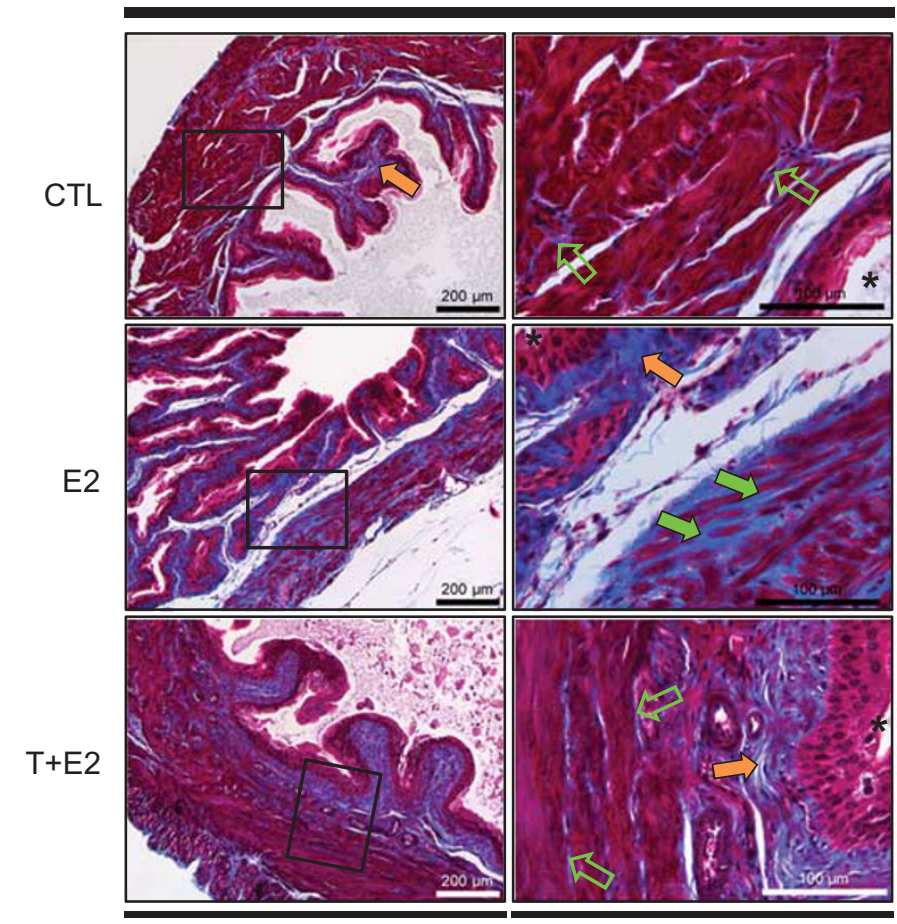

Low power

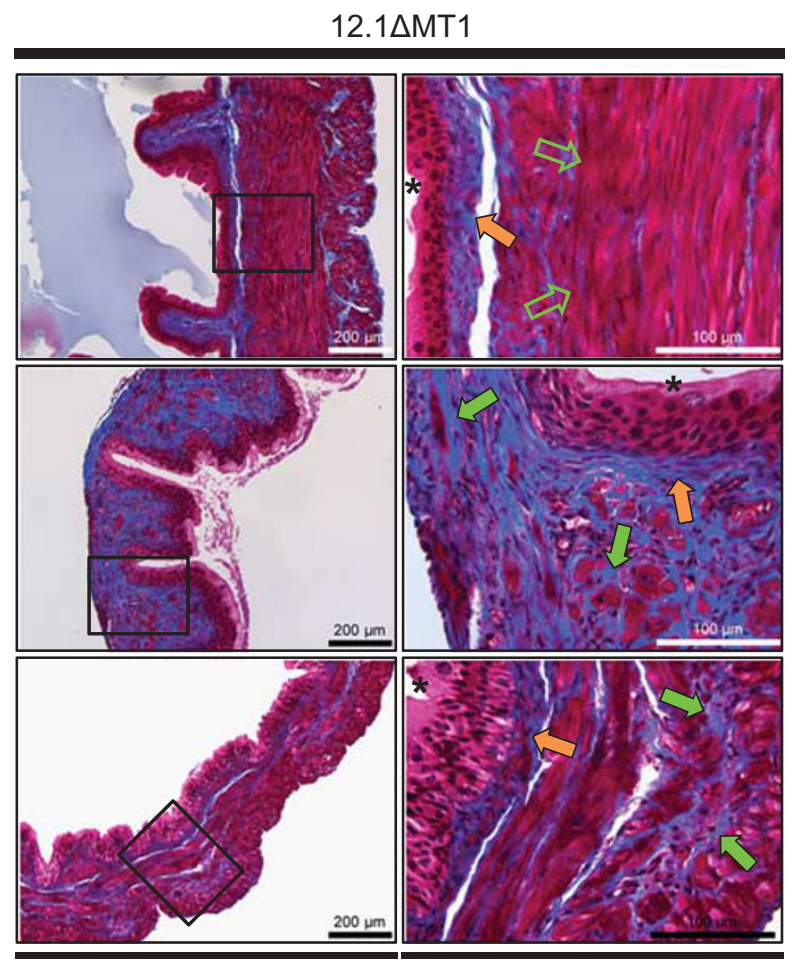

Low power

High power

b

Bladder neck

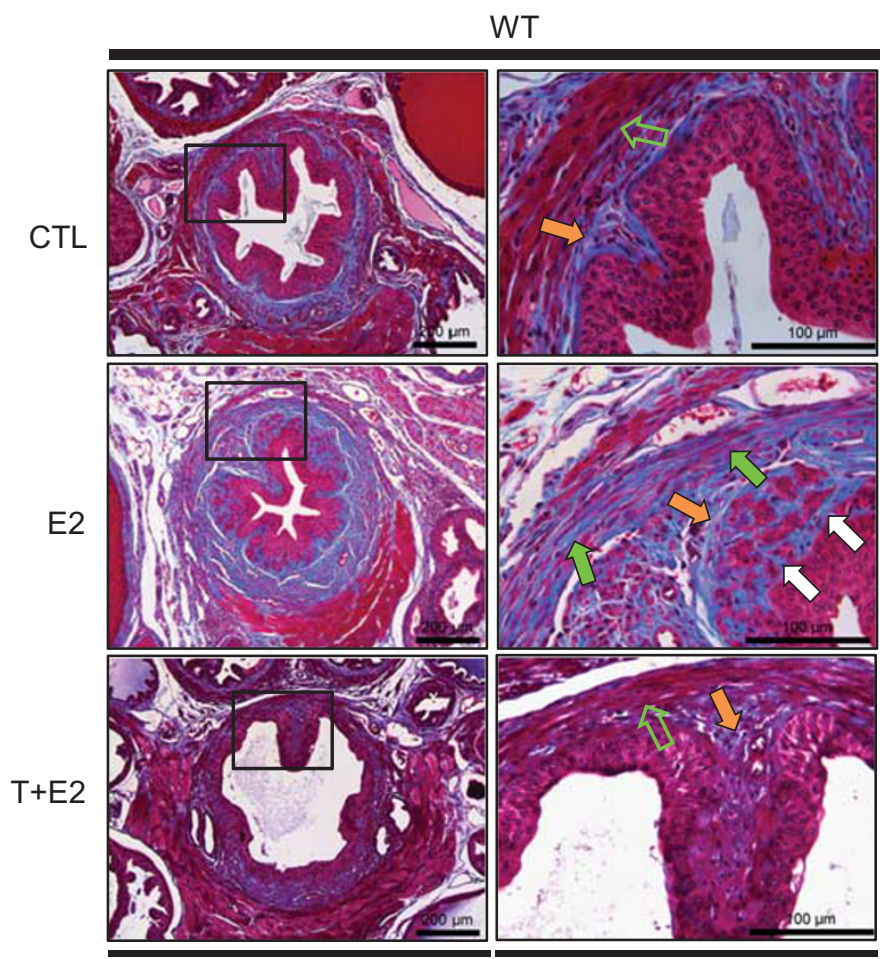

Low power
High power
12.1 $1 \mathrm{MT} 1$

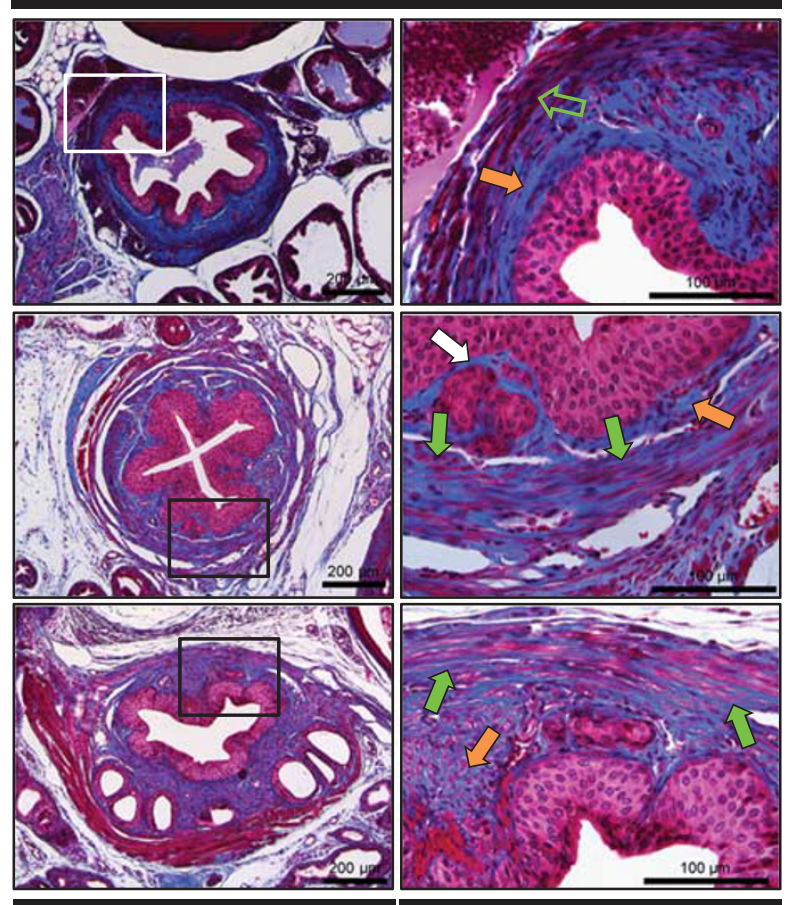

Low power

High power

Figure 5 For caption see page 553. 
Estrogens Induced Basal Cell Hyperplasia in the Bladder and Urethra of 12.1 $\triangle \mathrm{MT} 1$ Mice

To determine if $\mathrm{E} 2$ or $\mathrm{T}+\mathrm{E} 2$ increased cell proliferation in the LUT, we assessed the expression of Ki67 in bladder body, bladder neck, and proximal urethra (Figure 6). E2 alone, but not T+E2, caused a marked increase in Ki67 immunostaining in the basal layer of the bladder-body urothelium and urethral epithelium of $12.1 \Delta \mathrm{MT} 1$ mice but not in WT mice. a
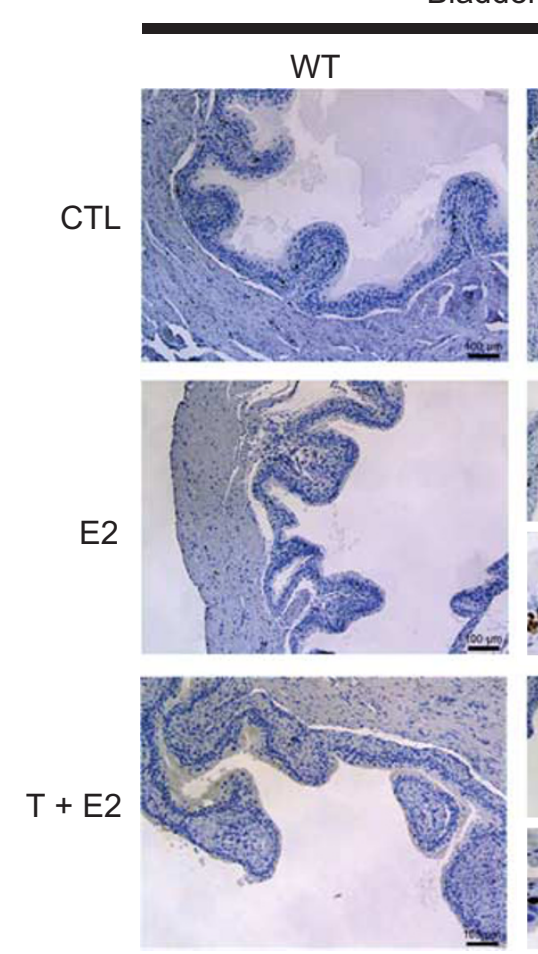
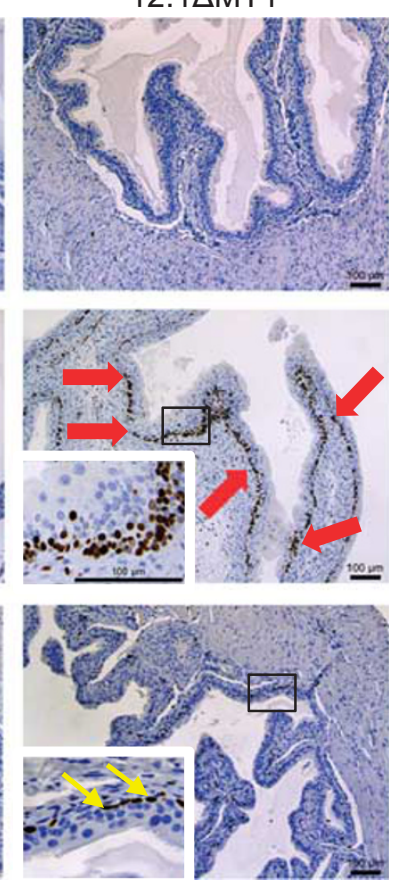

b
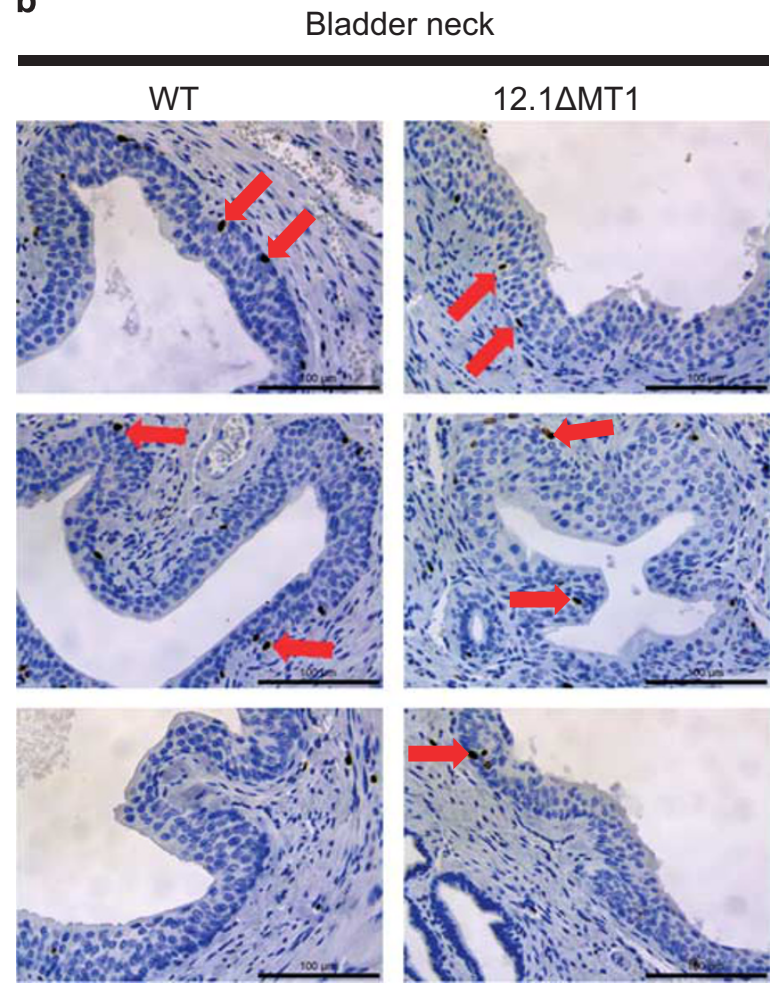

C

Proximal urethra
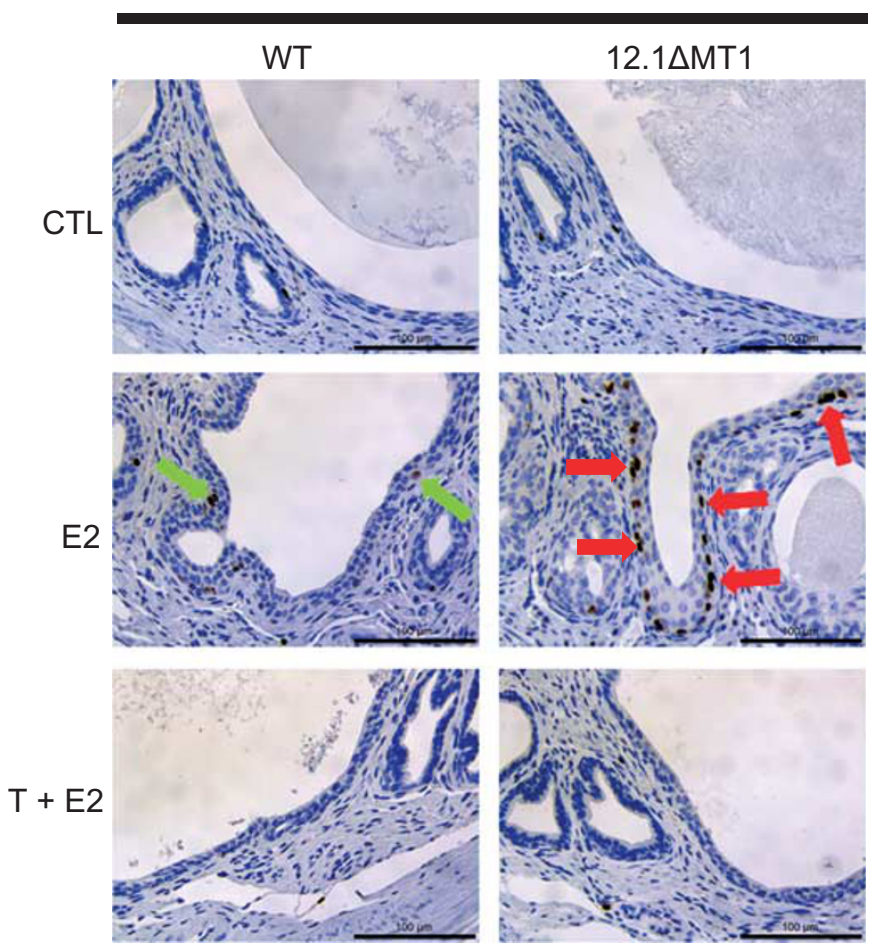

Figure 6 For caption see page 556. 


\section{High Basal Levels of NMDAR2A Expression in the LUT of 12.1 $\triangle \mathrm{MT} 1$ Mice}

To test a hypothesis that the deleted region contains putative regulatory DNA element(s) regulating neighboring genes, we checked the expression of NMDAR2A, a subunit of the NMDA receptor, which is encoded by Grin $2 a$ that is closest to the deleted site. NMDAR2A staining in the urothelium of the bladder body was weak, with no differences between 12.1 $\triangle \mathrm{MT1}$ and WT mice (Figures $7 \mathrm{a}$ and $\mathrm{b}$ ). Levels of NMDAR2A staining in the urothelium and smooth muscle layers of the bladder neck were higher in $12.1 \Delta \mathrm{MT} 1$ than in WT mice (Figures $7 \mathrm{c}$ and $\mathrm{d}$ ). NMDAR2A staining in neurons around the bladder-neck region was stronger in $12.1 \Delta \mathrm{MT} 1$ mice than in WT mice (Figures $7 \mathrm{e}$ and $\mathrm{f}$ ). In proximal urethra, intense NMDAR2A staining was localized to the urethral epithelium of $12.1 \Delta \mathrm{MT} 1$ mice, whereas such staining was very weak or negligible in WT mice (Figures $7 \mathrm{~g}$ and h). Treatment with E2, T+E2, T, BPA, or T + BPA did not alter the pattern and intensity of the NMDAR2A staining in the LUT of $12.1 \Delta \mathrm{MT} 1$ and WT mice as compared with that of the respective untreated control mice $(\mathrm{E} 2$ and $\mathrm{T}+\mathrm{E} 2$ panels shown in Supplementary Figure S3; T, BPA, and T + BPA panels not shown).

\section{DISCUSSION}

We present here a serendipitous finding that transgenic male mice expressing MT1 in the prostate gland exhibit a strong propensity for estrogen-induced BOO. The $12.1 \Delta \mathrm{MT} 1$ mice carry a homozygous MT1 transgene insertion with a concomitant 12.1-kb noncoding deletion at an intergenic region $\sim 36 \mathrm{~kb}$ upstream of Grin2a and displayed an increase in NMDAR2A, a subunit of the NMDA ionotropic glutamate receptor encoded by Grin2a, in the LUT. Bioinformatic analysis revealed several highly conserved (in mammals) putative regulatory DNA-like elements in the 12.1 -kb deleted region. After 4-6 months of treatment with $\mathrm{E} 2$ or $\mathrm{T}+\mathrm{E} 2$, the majority of $12.1 \Delta \mathrm{MT} 1$ mice had an enlarged bladder with urinary retention, accompanied by a thin detrusor, prominent fibrosis in the bladder body and neck, and basal cell hyperplasia in the bladder urothelium and urethral epithelium. Treatment with E2 alone narrowed the lumen of the bladder neck and proximal urethra more markedly in 12.1 $\triangle \mathrm{MT} 1$ mice than in WT mice despite prostate regression in both types of mice. A noticeable effect of T+E2 on the bladder neck narrowing was also noted in $12.1 \Delta \mathrm{MT} 1 \mathrm{mice}$.
To our knowledge, this is the first study in an animal model to document estrogen induction of bladder-neck anomalies in $\mathrm{BOO}$ that is not associated with an enlarged prostate. On the basis of these findings, we propose that these genetically modified mice represent a novel animal model for exploring the role of genetic determinants of susceptibility and severity in BOO associated with sex hormonal imbalance towards estrogen predominance.

Imbalance between androgens and estrogens has been recognized as a culprit in prostatic diseases such as $\mathrm{BPH}$ and prostate cancers. ${ }^{12,14,22}$ However, the hormonal etiology of bladder- and urethra-related LUTS remains poorly understood. Combined treatment with T and E2 resulted in elevated serum levels of E2 and maintained the physiologic levels of $\mathrm{T}$ in rodents. ${ }^{13,23}$ This method of hormonal manipulation mimics the changes of the ratio of $\mathrm{T}$ to $\mathrm{E} 2$ ratio in aging men, ${ }^{13,14}$ which is closely correlated with increasing prevalence of LUTS in men. ${ }^{3}$ Cotreatment with $\mathrm{T}$ and $\mathrm{E} 2$ has been shown to induce obstructive voiding in rats ${ }^{23}$ and $\mathrm{BOO}$ in mice. ${ }^{12}$ The hormone-induced growth of prostate tissue in the periurethral region may cause urethral narrowing and BOO, which is analogous to LUTS because of BPH in elderly men. In the present study, the majority of $12.1 \Delta \mathrm{MT} 1$ mice treated with $\mathrm{T}+\mathrm{E} 2$ developed severe $\mathrm{BOO}$, as characterized by an enlarged bladder with urinary retention $>1 \mathrm{ml}$ and a small bladder-neck lumen. It was somewhat surprising that $\mathrm{T}+\mathrm{E} 2$-treated $\mathrm{WT}$ mice did not exhibit the $\mathrm{BOO}$ phenotype, whereas a recent study ${ }^{12}$ demonstrated $\mathrm{BOO}$ induction in male mice by $\mathrm{T}+\mathrm{E} 2$ treatment. We used the same mouse strain $(\mathrm{C} 57 \mathrm{BL} / 6)$ and hormone doses (T: $25 \mathrm{mg}$ and E2: $2.5 \mathrm{mg}$ ) as Nicholson et $a l,{ }^{12}$ but a different type of hormone implant: silastic hormone capsules (as reported herein) vs compressed hormone pellets. ${ }^{12}$ Perhaps, the different outcomes in hormonal induction of $\mathrm{BOO}$ of these studies were due to different rates of hormone release by silastic and pellet implants. Our data for silastic implants clearly demonstrated that $12.1 \Delta \mathrm{MT} 1$ mice are more susceptible and sensitive to BOO induction as a consequence of elevated E2 in physiologic settings of androgens.

E2 treatment alone caused severe $\mathrm{BOO}$ and prostate gland regression in male $12.1 \Delta \mathrm{MT} 1$ mice. It should be noted that the prostate is not expressing the transgene MT1 in the E2-treated animal, further supporting the lack of relationship of urologic symptoms to MT1 or prostate enlargement.

Figure 6 Effects of testosterone (T) plus $17 \beta$-estradiol (E2) and T+E2 treatment on cell proliferation of the (a) bladder body, (b) bladder neck, and (c) proximal urethra of WT and 12.1 MMT1 mice. (a) Ki67 staining was abundant in the basal layers of urothelium in $12.1 \Delta \mathrm{MT1}$ mice treated with E2 (red arrows and inset), whereas only sporadic in the basal layer of urothelium in 12.1 $\Delta \mathrm{MT1}$ mice treated with T + E2 (inset, yellow arrows). Ki67-positive cells were rare in the bladders of untreated 12.1 $\Delta \mathrm{MT1}$ mice and WT mice treated with E2 or T + E2. (b) Ki67-positive nuclear staining was occasionally observed in the bladder-neck urothelium of untreated control WT and 12.1 $\Delta$ MT1 mice (red arrows). Treatment with E2 or T+E2 did not cause any noticeable changes in the Ki67 staining pattern in the bladder neck of WT or $12.1 \Delta$ MT1 mice. (c) Ki67 staining was located in the basal layers of urethral epithelium in 12.1 $\Delta \mathrm{MT} 1$ mice treated with E2 (red arrows). Scant Ki67 staining was found in WT mice treated with E2 (green arrows). Ki67staining was absent or rare in untreated or T+E2-treated WT or 12.1 $\Delta$ MT1 mice. Scale bar: $100 \mu \mathrm{m}$. MT1, metallothionein-1. 
The narrowing of bladder outlet and urinary obstruction in these mice could not be because of BPH, which is regarded as a primary cause of $\mathrm{BOO}$ in men. Given that estrogen receptors are present in the male LUT, including the bladder and urethra, ${ }^{6,24-26}$ it is plausible that extraprostatic tissues in the LUT are direct site(s) of estrogenic actions in BOO development. The pathophysiologic effect of E2, which is independent of prostate growth promotion, in $\mathrm{BOO}$ development has been shown in transgenic mice overexpressing aromatase. ${ }^{6,27}$ Epidemiologic studies did not reveal a statistically significant correlation between the severity of BOO symptoms and prostate size. ${ }^{4,28}$ Thus, the underlying causes of $\mathrm{BOO}$ are heterogeneous and more complex than previously appreciated and may involve 'non-prostatic' mechanisms.

Epidemiologic studies investigating the relationship between androgens and LUTS yielded conflicting results. Serum levels of $\mathrm{T}$ have been inversely related to the severity and risk of LUTS in men. ${ }^{9,10,29}$ However, such associations were not observed in other studies. ${ }^{8,30,31}$ In our study, $\mathrm{T}+\mathrm{E} 2$ treatment resulted in a lower incidence of severe BOO (as characterized by urinary retention, bladder outlet luminal sizes and amounts of collagen deposit) than E2-alone treatment in both $\mathrm{WT}$ and $12.1 \Delta \mathrm{MT} 1$ mice. The T supplement appeared to alleviate $\mathrm{BOO}$ symptoms in mice having elevated E2 exposures. In a study with $\mathrm{BOO}$ patients,
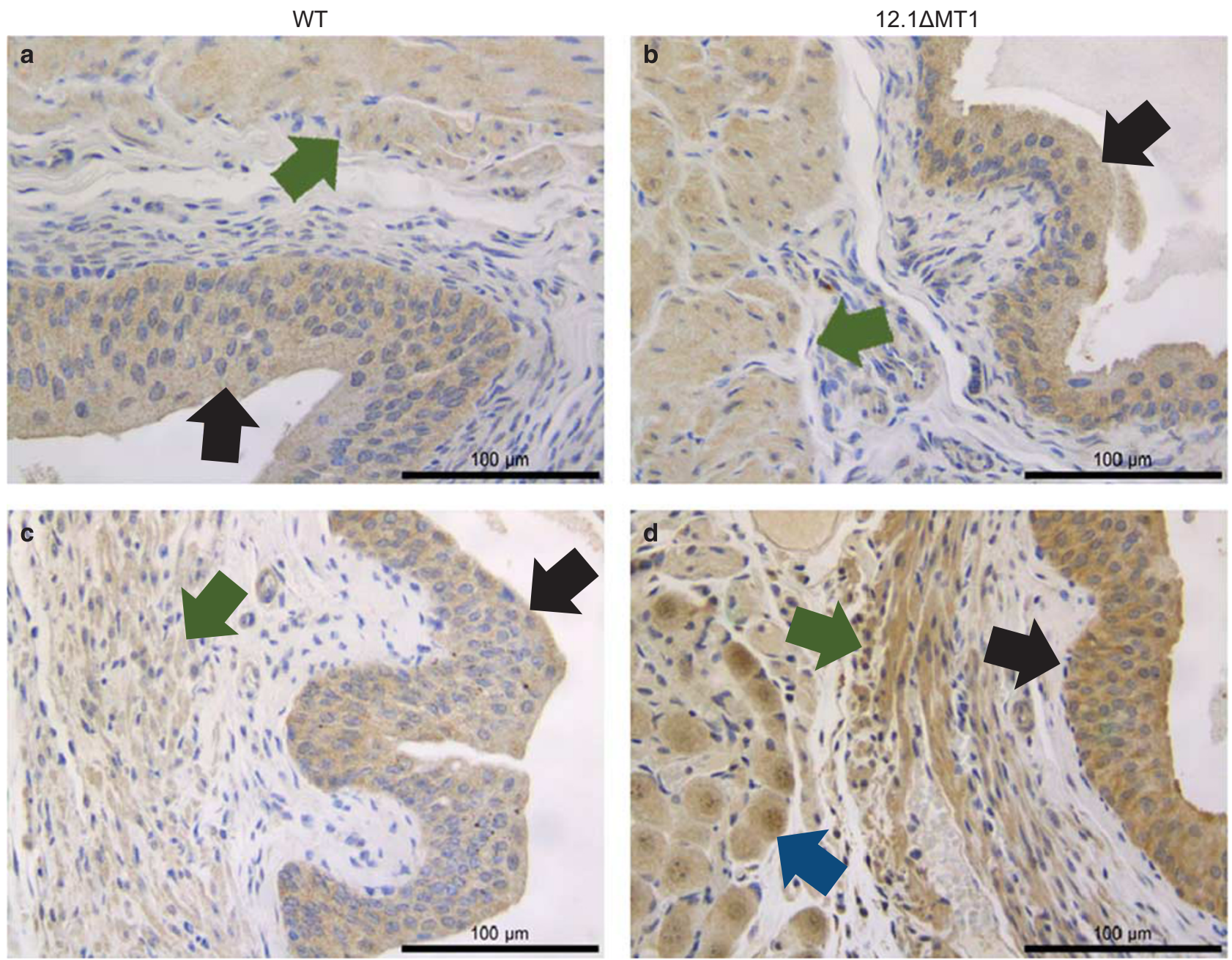

Figure 7 NMDAR2A (NMDA receptor subunit encoded by Grin2a) immunohistochemistry in the lower urinary tract of untreated wild-type (WT) and $12.1 \Delta \mathrm{MT} 1$ control mice. (a and $\mathbf{b})$ Bladder body. Staining is weak in the urothelium and detrusor of the bladders of WT (a) and $12.1 \Delta \mathrm{MT} 1$ (b) mice. No staining is evident in the lamina propria of WT and 12.1 $\Delta \mathrm{MT1}$ mice. (c and d) Bladder neck. As compared with the staining of the bladder neck of WT mice (c), localized staining is abundant in the urothelium and detrusor in the bladder-neck region of $12.1 \Delta \mathrm{MT1}$ mice (d). A cluster of neuronal cells associated with the bladder neck of $12.1 \Delta \mathrm{MT} 1$ mice also shows intense staining (d). (e and f) Bladder neck. Immunostaining is absent in neuronal cells in the bladder-neck region of WT mice (e), whereas immunostaining is strong in that of $12.1 \Delta \mathrm{MT} 1$ mice (f). (g and $\mathbf{h})$ Proximal urethra. No staining is detected in the urethral epithelium and stroma of WT mice (g), whereas strong staining is restricted to the urethral epithelium of 12.1 $\Delta \mathrm{MT1}$ mice (h). Scale bar: $100 \mu \mathrm{m}$. Black arrows: urothelium; green arrows: detrusor; blue arrows: neuronal cells; open arrows: urethral epithelium. MT1, metallothionein-1. 

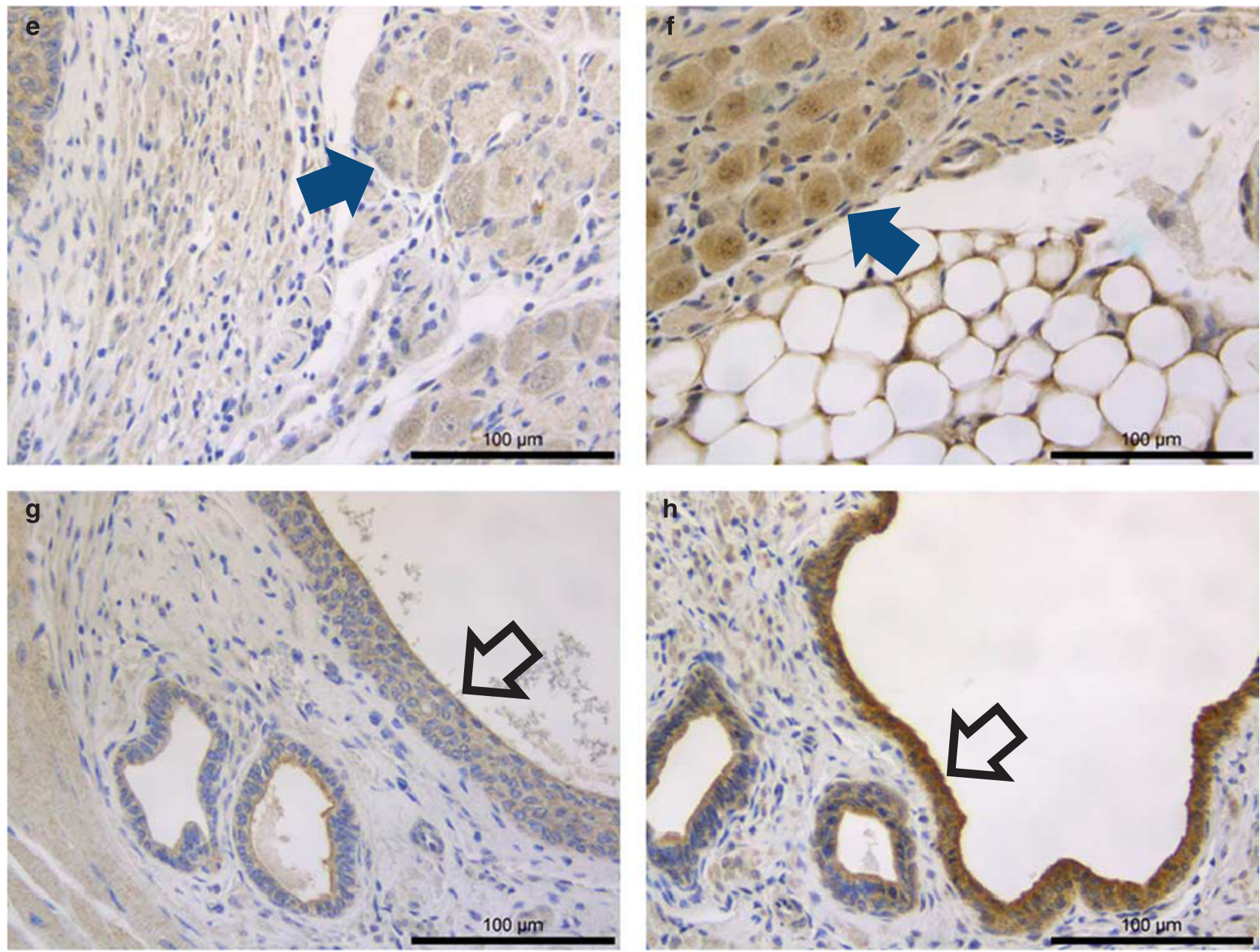

Figure 7 Continued.

low $\mathrm{T}$ levels were associated with unfavorable manifestations of BOO, ${ }^{11}$ suggesting that androgens may have ameliorating effects in LUT function. In contrast, in a rat study with E2 treatment plus different doses of $\mathrm{T}$, obstructive voiding was only observed in treated rats with hyperandrogenic state but not in those with hypoandrogenic state. ${ }^{32}$

The $12.1 \Delta \mathrm{MT} 1$ mice carry a genomic alteration targeted at an intergenic region adjacent to Grin2a. The genomic modification includes an insertion of a transgene cassette expressing MT1 under probasin promoter and a concomitant deletion of a $\sim 12.1-\mathrm{kb}$ genomic region. Although the transgene activation is restricted to the prostate gland and tightly regulated by androgens, the low abundance of transgene MT1 relative to the endogenous levels would discount the contribution of the transgene to prostate and LUT pathology. In addition, the BOO phenotype was not observed in T-treated 12.1 $\Delta \mathrm{MT} 1$ mice, in which high levels of transgene expression were expected. In contrast, severe $\mathrm{BOO}$ was induced by treatment with $\mathrm{E} 2$, which would markedly reduce endogenous androgens and hence transgene expression. The hormonal induction of $\mathrm{BOO}$ appears to be independent of $M T-1$ transgene expression.

A notable feature of the $12.1 \Delta \mathrm{MT} 1$ mice is the increased expression of NMDAR2A in the bladder neck and urethra. NMDA is a glutamate-gated ion channel that exhibits high calcium permeability and voltage-dependent sensitivity to magnesium. These receptors are present in the nervous system and in non-neuronal cells/tissues, including male LUT. $^{33}$ In addition to their well-characterized role in the central nervous system, NMDA receptors are known to control external urethral sphincter activity via the glutamate mechanisms of the micturition reflex pathway. ${ }^{20}$ Until now, few studies on the pathophysiologic role of NMDA receptors in $\mathrm{BOO}$ or voiding dysfunction have been reported. In a rat study, surgically induced BOO caused NMDA receptormediated changes in the bladder afferent pathway. ${ }^{34}$

The observed elevation in the levels of NMDAR2A protein in urinary tract tissues of $12.1 \Delta \mathrm{MT} 1$ mice raises the questions of how the genomic modification at an intergenic region leads to activation of Grin2a and how NMDAR2A 
modifies the BOO risk and susceptibility. In this context, it is intriguing to note that several highly conserved (in mammals) noncoding elements are located within the $12.1-\mathrm{kb}$ deleted region. The conservation within the deleted region is quite extensive between humans and mice: a number of shorter fragments and three relatively long regions of the deleted region (with the total length of $>2 \mathrm{~kb}$ and sequence identity $>60 \%$ ) align with very significant $E$-values using BLASTn. Moreover, DNase I hypersensitivity clusters, as markers of regulatory DNA elements, ${ }^{18}$ were mapped in the human counterpart of the deleted region by the ENCODE project. In an attempt to limit the false-positive rate in the prediction of putative functional sites, ECR browser was used to map evolutionary conserved (between human and mouse) regions within the deleted fragment. Subsequently, rVista was used to identify conserved TF binding sites in these regions. The longest conserved region identified within the deleted region by ERC extends for about $700 \mathrm{bp}$, and starts at position 7634 in the deleted region (mouse chr 16: 9532 818-9533533, corresponding to human chr 16: 9798 1479798 847; see also Supplementary Figure S1). The conserved region contains several conserved LEF-1/TCF family binding sites (CTTTGWW, where $\mathrm{W}$ is either $\mathrm{A}$ or $\mathrm{T}$ ), as identified by rVista and depicted in Supplementary Figure S1. Based on recent high-throughput screening for TF binding sites associated with ER binding sites ERE, LEF-1 has been found to have the highest degree of colocalization with ER enhancers. It appears that typically LEF1/TCF inhibits ER-mediated transcription, so the loss of LEF1/TCF sites could result in increased ER-regulated transcription. However, a direct estradiol effect on LEF1/TCF-mediated regulation, independent of ER transcriptional activity, has also been suggested. ${ }^{35}$

However, our data suggest that augmented NMDAR2A expression alone is not sufficient for BOO development, whereas such high basal levels of this gene in the LUT may render the $12.1 \Delta \mathrm{MT} 1$ mice more susceptible to estrogeninduced $\mathrm{BOO}$ and exacerbate the disease severity. Future investigations are warranted to identify and validate specific regulatory DNA elements that regulate $\mathrm{BOO}$-associated gene networks and hence to gain insights into disease mechanisms.

Characteristic features of the BOO phenotype in the 12.1 $\triangle \mathrm{MT} 1$ mouse model are the bladder-neck anomalies, as indicated by the bladder-neck narrowing, fibrosis and ectopic NMDAR2A expression in the urothelium, smooth muscles, and neuronal cells of the bladder-neck region. Prostate and bladder-neck hyperplasia was not observed in E2-treated mice showing a high incidence of severe BOO, suggesting that bladder-neck narrowing may not be caused by mechanical obstruction. However, it is possible that hyperplasia in the proximal urethra is a culprit of urethral narrowing leading to an obstruction of LUT. Additionally, prominent fibrosis is evident in the smooth muscle layer and urothelium of bladder neck following chronic exposure to E2. To our knowledge, this is the first time to report bladder-neck fibrosis associated with BOO. The bladder-body detrusor fibrosis has been reported in rodents with surgical obstruction of urethra, ${ }^{36-38}$ aromatase-overexpressing mice ${ }^{6}$ and $\mathrm{T}+\mathrm{E} 2$-treated mice. ${ }^{12}$ The abnormal deposition of collagen in the bladder neck and body, as a consequence of urinary obstruction, may further increase the stiffness and matrix rigidity of LUT leading to the decompensated stage of BOO. Intriguingly, the conjunct action of $\mathrm{T}$ appeared to be protective in attenuating the effects of E2 on LUT fibrogenesis.

Thin detrusor wall is a peculiar feature of estrogenexposed bladders, as reported by us and others. ${ }^{6,12}$ Although the bladder wall thickening is regarded as a phenotypic response to surgical obstruction of urethra in partial $\mathrm{BOO}$ animal models, ${ }^{39}$ it remains uncertain if the measurement of bladder wall thickness is a reliable diagnostic criterion for BOO assessment in men. ${ }^{40,41}$ As a limitation, detrusor thickness varies with the urine volume in bladder filling. ${ }^{40}$

In humans, primary bladder-neck obstruction (PBNO), first described by Marion in $1933,{ }^{42}$ is a condition in which the bladder neck fails to open during voiding without other anatomic obstruction, such as in $\mathrm{BPH}$ in men. ${ }^{5} \mathrm{PBNO}$ is recognized as a major cause of voiding dysfunction in young men $^{5}$ and is also found in women and children. ${ }^{43}$ The bladder-neck samples from patients with PBNO showed an increased in the number of neuropeptide Y-immunoreactive nerves, suggesting sympathetic nervous dysfunction in bladder-neck smooth muscle. ${ }^{44}$ The $12.1 \Delta \mathrm{MT} 1$ mice represent an animal model of bladder-neck obstruction that is clinically relevant to human $\mathrm{BOO}$ with hormonal and/or neurologic etiologies.

In summary, the $12.1 \Delta \mathrm{MT} 1$ mice possess a defined genomic modification and exhibit increased susceptibility and severity of estrogen-induced $\mathrm{BOO}$ that is not associated with $\mathrm{BPH}$. This novel animal model provides an opportunity to identify genetic determinants and underlying mechanisms for modifying the risk of $\mathrm{BOO}$ and to design new pharmacologic intervention strategies.

Supplementary Information accompanies the paper on the Laboratory Investigation website (http://www.laboratoryinvestigation.org)

\section{ACKNOWLEDGMENTS}

We thank Dr Susan Kasper for rat probasin promoter and Nancy K Voynow for excellent editing of this manuscript. We are grateful to Miss Agnes Cheong for her assistance to prepare RNA, and to conduct reverse transcription and GPCR. We also thank Miss Lisa McMillin and Miss Kelley Stanley for histological slide preparation and Masson's Trichrome stain, respectively. This work was supported, in part, by R01CA062269, R01CA015776, R01CA112532, R01ES015584, R01ES022071, U01ES019480, U01ES020988, P30ES006096, and 101BX000675 awarded to SMH; R21CA156042 awarded to NT; and R01CA122346, R21Al097936, and UL1RR026314 awarded to JM.

\section{DISCLOSURE/CONFLICT OF INTEREST}

The authors declare no conflict of interest.

1. Roehrborn CG. Male lower urinary tract symptoms (LUTS) and benign prostatic hyperplasia (BPH). Med Clin N Am 2011;95:87-100. 
2. Platz EA, Smit E, Curhan GC, et al. Prevalence of and racial/ethnic variation in lower urinary tract symptoms and noncancer prostate surgery in U.S. men. Urology 2002;59:877-883.

3. Parsons JK. Benign prostatic hyperplasia and male lower urinary tract symptoms: epidemiology and risk factors. Curr Bladder Dysfunct Rep 2010;5:212-218.

4. Tsukamoto T, Kumamoto $\mathrm{Y}$, Masumori N, et al. Prevalence of prostatism in Japanese men in a community-based study with comparison to a similar American study. J Urol 1995;154:391-395.

5. Nitti VW. Primary bladder neck obstruction in men and women. Rev Urol 2005;7:S12-S17.

6. Lin W, Rahman NA, Lin J, et al. Molecular mechanisms of bladder outlet obstruction in transgenic male mice overexpressing aromatase (Cyp19a1). Am J Pathol 2011;178:1233-1244.

7. Lepor $\mathrm{H}$. Pathophysiology of lower urinary tract symptoms in the aging male population. Rev Urol 2005;7:S3-S11.

8. Rohrmann S, Nelson WG, Rifai $\mathrm{N}$, et al. Serum sex steroid hormones and lower urinary tract symptoms in Third National Health and Nutrition Examination Survey (NHANES III). Urology 2007;69:708-713.

9. Trifiro MD, Parsons JK, Palazzi-Churas K, et al. Serum sex hormones and the 20-year risk of lower urinary tract symptoms in communitydwelling older men. BJU Int 2010;105:1554-1559.

10. Litman $\mathrm{HJ}$, Bhasin S, O'Leary MP, et al. An investigation of the relationship between sex-steroid levels and urological symptoms: results from the Boston Area Community Health survey. BJU Int 2007; 100:321-326.

11. Koritsiadis G, Stravodimos K, Mitropoulos D, et al. Androgens and bladder outlet obstruction: a correlation with pressure-flow variables in a preliminary study. BJU Int 2008;101:1542-1546.

12. Nicholson TM, Ricke EA, Marker PC, et al. Testosterone and 17betaestradiol induce glandular prostatic growth, bladder outlet obstruction, and voiding dysfunction in male mice. Endocrinology 2012;153: 5556-5565.

13. Ricke WA, Ishii K, Ricke EA, et al. Steroid hormones stimulate human prostate cancer progression and metastasis. Int J Cancer 2006;118: 2123-2131.

14. Ricke WA, McPherson SJ, Bianco JJ, et al. Prostatic hormona carcinogenesis is mediated by in situ estrogen production and estrogen receptor alpha signaling. FASEB J 2008;22:1512-1520.

15. Ho SM, Tang WY, Belmonte de FJ, et al. Developmental exposure to estradiol and bisphenol A increases susceptibility to prostate carcinogenesis and epigenetically regulates phosphodiesterase type 4 variant 4. Cancer Res 2006;66:5624-5632.

16. Rohrmann S, Fallin MD, Page WF, et al. Concordance rates and modifiable risk factors for lower urinary tract symptoms in twins. Epidemiology 2006;17:419-427.

17. Helfand BT, $\mathrm{Hu} \mathrm{Q}$, Loeb $\mathrm{S}$, et al. Genetic sequence variants are associated with severity of lower urinary tract symptoms and prostate cancer susceptibility. J Urol 2013;189:845-848.

18. Maurano MT, Humbert R, Rynes $E$, et al. Systematic localization of common disease-associated variation in regulatory DNA. Science 2012;337:1190-1195.

19. Tekur S, Ho SM. Ribozyme-mediated downregulation of human metallothionein $\mathrm{Il}(\mathrm{a})$ induces apoptosis in human prostate and ovarian cancer cell lines. Mol Carcinogen 2002;33:44-55.

20. Fowler CJ, Griffiths D, de Groat WC. The neural control of micturition Nat Rev Neurosci 2008;9:453-466.

21. Andriani F, Nan B, Yu J, et al. Use of the probasin promoter ARR2PB to express Bax in androgen receptor-positive prostate cancer cells. J Nat Cancer Inst 2001;93:1314-1324.

22. Leav I, Galluzzi CM, Ziar J, et al. Mitogen-activated protein kinase and mitogen-activated kinase phosphatase-1 expression in the Noble rat model of sex hormone-induced prostatic dysplasia and carcinoma. Lab Invest 1996;75:361-370.

23. Bernoulli J, Yatkin E, Talvitie EM, et al. Urodynamic changes in a noble rat model for nonbacterial prostatic inflammation. Prostate 2007;67: 888-899.
24. Salmi S, Santti R, Gustafsson JA, et al. Co-localization of androgen receptor with estrogen receptor beta in the lower urinary tract of the male rat. J Urol 2001;166:674-677.

25. Chavalmane AK, Comeglio P, Morelli A, et al. Sex steroid receptors in male human bladder: expression and biological function. J Sex Med 2010;7:2698-2713.

26. Lehtimaki J, Makela S, Viljamaa J, et al. Neonatal estrogenization of the male mouse results in urethral dysfunction. J Urol 1996;156: 2098-2103.

27. Streng $\mathrm{T}$, Li $\mathrm{X}$, Lehtoranta $\mathrm{M}$, et al. Infravesical obstruction in aromatase over expressing transgenic male mice with increased ratio of serum estrogen-to-androgen concentration. J Urol 2002;168. 298-302.

28. Barry MJ, Cockett AT, Holtgrewe HL, et al. Relationship of symptoms of prostatism to commonly used physiological and anatomical measures of the severity of benign prostatic hyperplasia. J Urol 1993;150: 351-358.

29. St Sauver JL, Jacobson DJ, McGree ME, et al. Associations between longitudinal changes in serum estrogen, testosterone, and bioavailable testosterone and changes in benign urologic outcomes. Am J Epidemiol 2011;173:787-796.

30. Schatzl G, Brossner C, Schmid S, et al. Endocrine status in elderly men with lower urinary tract symptoms: correlation of age, hormonal status, and lower urinary tract function. The Prostate Study Group of the Austrian Society of Urology. Urology, 552000 397-402.

31. Miwa Y, Kaneda T, Yokoyama O. Association between lower urinary tract symptoms and serum levels of sex hormones in men. Urology 2008:72:552-555.

32. Bernoulli J, Yatkin E, Konkol Y, et al. Prostatic inflammation and obstructive voiding in the adult Noble rat: impact of the testosterone to estradiol ratio in serum. Prostate 2008;68:1296-1306.

33. Gonzalez-Cadavid NF, Ryndin I, Vernet D, et al. Presence of NMDA receptor subunits in the male lower urogenital tract. J Androl 2000;21:566-578.

34. Tanaka $\mathrm{H}$, Kakizaki $\mathrm{H}$, Shibata $\mathrm{T}$, et al. Effects of chronic blockade of $N$-methyl-D-aspartate receptors by MK-801 on neuroplasticity of the micturition reflex pathway after partial urethral obstruction in the rat. J Urol 2003;170:1427-1431.

35. Holmes KA, Song JS, Liu XS, et al. Nkx3-1 and LEF-1 function as transcriptional inhibitors of estrogen receptor activity. Cancer Res 2008;68:7380-7385

36. Ekman M, Bhattachariya A, Dahan D, et al. Mir-29 repression in bladder outlet obstruction contributes to matrix remodeling and altered stiffness. PLoS One 2013;8:e82308.

37. Iguchi N, Hou A, Koul HK, et al. Partial bladder outlet obstruction in mice may cause E-cadherin repression through hypoxia induced pathway. J Urol 2014;192:964-972.

38. Austin JC, Chacko SK, DiSanto M, et al. A male murine model of partial bladder outlet obstruction reveals changes in detrusor morphology, contractility and Myosin isoform expression. J Urol 2004;172: 1524-1528.

39. Gabella G, Uvelius B. Urinary bladder of rat: fine structure of normal and hypertrophic musculature. Cell Tissue Res 1990;262:67-79.

40. Oelke $M$, Hofner $K$, Wiese $B$, et al. Increase in detrusor wall thickness indicates bladder outlet obstruction (BOO) in men. World J Urol 2002;19:443-452.

41. Blatt $\mathrm{AH}$, Titus J, Chan L. Ultrasound measurement of bladder wall thickness in the assessment of voiding dysfunction. J Urol 2008;179:2275-227.

42. Marion G. Surgery of the neck of the bladder. Br J Urol 1933;5:351-357.

43. Padmanabhan P, Nitti VW. Primary bladder neck obstruction in men, women, and children. Curr Urol Rep 2007;8:379-384.

44. Crowe R, Noble J, Robson T, et al. An increase of neuropeptide $Y$ but not nitric oxide synthase-immunoreactive nerves in the bladder neck from male patients with bladder neck dyssynergia. J Urol 1995;154 1231-1236. 